\title{
SÔBRE A PRIMEIRA MATURAÇÃO SEXUAL E DESTRUIÇÃO DE PEIXES IMATUROS
}

\author{
(Recebido em 6/6/61)
}

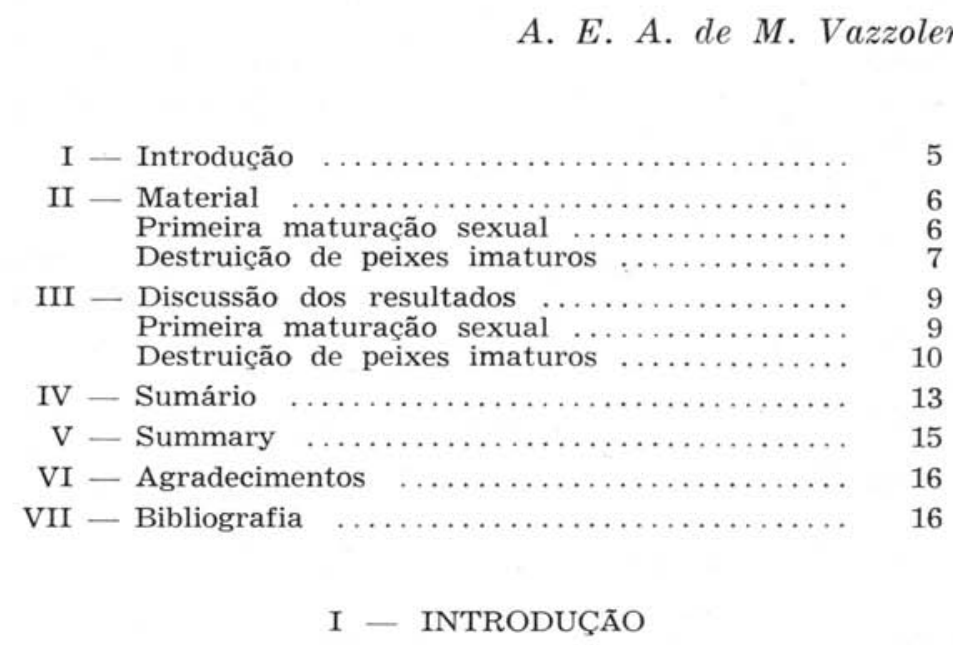

Êste trabalho apresenta os resultados obtidos no estudo do comprimento em que se inicia a primeira maturação sexual de algumas espécies de peixes, bem como a avaliação da quantidade de indivíduos imaturos destruídos pela frota comercial de Santos (barcos nacionais e estrangeiros). Foram estudadas quatro espécies que apresentam interêsse comercial:

a) sardinha-verdadeira - Sardinella allecia (Rafinesque, 1810) Fowler, 1941;

b) pescada-foguete - Macrodon ancylodon (Bloch, 1801) Jordan, Evermann \& Clark, 1930;

c) corvina - Micropogon furnieri (Desmarest, 1822) Jordan, 1884;

d) goete - Cynoscion petranus (Ribeiro, 1915) Lara, 1948.

* Instituto Oceanográfico da Universidade de São Paulo. Membro do Grupo de Pesquisas sôbre a Pesca Maritima (G.P.P.M.).

Publ. ne 161 do Inst. Ocean. da USP.

Contr. no 13 do G.P.P.M. 
Foram analisados os dados referentes a comprimento, maturidade sexual e número total de peixes desembarcados, para o período de agôsto de 1958 a dezembro de 1960, coletados no Entreposto de Pesca de Santos e no Cais do Macuco. Êste é o local de desembarque dos barcos da "Sociedade de Pesca Taiyo Ltda." (Braga, 1962).

Primeira maturação sexual - A coleta de dados sôbre maturidade sexual não foi iniciada simultâneamente para as diferentes espécies estudadas. Dêsse modo, o período analisado para cada espécie foi o seguinte:

a) sardinha-verdadeira: agôsto de 1958 a novembro de 1960, não tendo havido amostragem em dezembro de 1960 por falta de desembarque dessa espécie;

b) pescada-foguete: dezembro de 1958 a dezembro de 1960;

c) corvina: setembro de 1958 a dezembro de 1960;

d) goete: outubro de 1958 a dezembro de 1960.

Os dados sôbre comprimento referem-se ao comprimento total do peixe, medido da maneira descrita por Nomura (1960). Nas Tabelas e Figuras os dados foram agrupados de $1 \mathrm{em} 1 \mathrm{~cm}$, tendo-se introduzido a correção de $0,50 \mathrm{~cm}$.

Em relação à maturação sexual os espécimes foram divididos em dois grupos: o dos peixes imaturos, cujas gônadas são filamentares, translúcidas e pequenas, ocupando menos de um têrço da cavidade abdominal, estando situadas logo abaixo da coluna vertebral, e o dos peixes maduros, que inclui os que apresentam gônadas nos demais estádios de desenvolvimento.

Com os dados sôbre comprimento e maturidade, das amostras de laboratório, foram construídas as chaves comprimento-maturidade (Tabelas IA, IB, IC e ID), que fornecem a freqüência de cada grupo (imaturos e maduros) por classe de comprimento, respectivamente para a sardinha-verdadeira, a pescada-foguete, a corvina e o goete.

Com essas Tabelas construíram-se Figuras (1A, 1B, 1C e 1D), nas quais foram lançados os comprimentos na abscissa e, na ordenada, as porcentagens correspondentes aos maduros; o ponto de $50 \%$ forneceu o comprimento médio, interpolado, correspondente ao início da primeira maturação. 
Destruição de peixes imaturos - $\mathrm{O}$ número total de peixes (imaturos e maduros) desembarcados foi obtido do total desembarcado nos períodos de agôsto a dezembro de 1958, janeiro a dezembro de 1959 e janeiro a dezembro de 1960, pelos barcos nacionais e estrangeiros, isoladamente. A distribuição da freqüência, por classe de comprimento, foi feita segundo os dados obtidos no Entreposto (barcos nacionais) e no Cais do Macuco (barcos estrangeiros), considerados como representativos da distribuição dos peixes desembarcados. $\mathrm{O}$ número de indivíduos desembarcados por classe de comprimento foi distribuído para os grupos de peixes imaturos e maduros, de acôrdo com as freqüências obtidas nas chaves comprimento-maturidade (Tabelas IA, IB, IC e ID) para os barcos nacionais e estrangeiros. A seguir foi computado o número total de peixes imaturos e maduros desembarcados, por período.

Os peixes desembarcados pelos barcos nacionais não sofrem separação em categorias de tamanho, sendo descarregados a granel (Vazzoler, 1962). Os barcos nacionais são de diferentes tipos; assim sendo, considerou-se separadamente o número total de peixes desembarcados pelos "trawlers" de parelhas pequenas (parelhinhas de sol-a-sol) e pelos demais tipos de barcos ("trawlers" de porta grandes e médios, "trawlers" de porta pequenos ou baleeiras e "trawlers" de parelhas grandes e médias) para a pescada-foguete, a corvina e o goete. A sardinha é capturada ùnicamente pelas traineiras.

Na Tabela II tem-se o número total e a porcentagem de peixes imaturos e maduros desembarcados, por período, pelos barcos nacionais, referentes à sardinha-verdadeira, à pescada-foguete, à corvina e ao goete (Fig. 2) .

A pescada-foguete, a corvina e o goete são descarregados como espécies isoladas, pelos barcos nacionais, e também incluídas na mistura (Richardson \& Santos, 1962). Por isso considerou-se também os peixes descarregados em 1959 e 1960, incluídos na mistura. Êstes também foram distribuídos para os grupos de peixes imaturos e maduros, para as parelhinhas e demais barcos (Tabela III, Fig. 3).

Os barcos estrangeiros capturam quase que exclusivamente a pescada-foguete, seguida por pequena quantidade de corvina. Os peixes são descarregados em três categorias de tamanho: pequenos, médios e grandes. Dêsse modo considerou-se o número total e as porcentagens de peixes imaturos e maduros desembarcados por período e por categoria (Tabela IV, Fig. 4).

A Tabela $\mathrm{V}$ apresenta o número total e a porcentagem de pescada-foguete e corvina desembarcadas, por período, pelos bar- 
cos nacionais e estrangeiros, incluindo a espécie isolada e a englobada na mistura, bem como as três categorias de tamanho (Fig. 5).

Parte do total de peixes capturados pelas rêdes de pesca é rejeitada e devolvida morta ao mar, por se tratar de peixes pequenos, sem valor comercial. Para a sardinha-verdadeira não se verifica rejeição. Para as outras três espécies os comprimentos máximos observados para os exemplares não aproveitados foram: $16 \mathrm{~cm}$ para a pescada-foguete; $17 \mathrm{~cm}$ para a corvina e $16 \mathrm{~cm}$ para o goete (Moreira, em preparação).

Comparando-se essas medidas com aquelas obtidas para o início da primeira maturação, observa-se que a totalidade dos peixes rejeitados é constituída por imaturos.

A rejeição de peixes só ocorre nos barcos nacionais, onde a malhagem das rêdes é pequena $(36 \mathrm{~mm})$. Nos barcos estrangeiros a malhagem é bem maior $(68 \mathrm{~mm})$, e o pescado capturado é desembarcado em quase sua totalidade.

Os dados de Moreira sôbre a porcentagem em número de indivíduos aproveitados e rejeitados pelas parelhinhas são os seguintes: a) pescada-foguete: $36 \%$ aproveitados e $64 \%$ rejeitados; b) corvina: $73 \%$ aproveitados e $27 \%$ rejeitados; c) goete: $56 \%$ aproveitados e $44 \%$ rejeitados. Com êsses dados e com aquêles das Tabelas II e III (colunas referentes às parelhinhas) calculou-se as porcentagens de peixes imaturos e maduros para o total capturado por êsse tipo de barco, por período (Tabela VI, Fig. 6).

Como os demais tipos de barcos nacionais operam com rêdes de mesma malhagem $(36 \mathrm{~mm})$ que as parelhinhas, foram consideradas as porcentagens de peixes aproveitados e rejeitados referidas acima como porcentagens médias para os demais tipos de barcos nacionais. Para o cálculo da porcentagem de peixes imaturos destruídos em relação ao total capturado operou-se com as porcentagens de peixes aproveitados e rejeitados; nota-se que a totalidade dêsses últimos é constituída de imaturos. Para o aproveitado a porcentagem foi distribuída para os grupos de imaturos e maduros, segundo o número de peixes. A seguir foi computada a porcentagem total de imaturos e maduros. A Tabela VII mostra a distribuição percentual dos peixes imaturos e maduros, em relação ao total capturado, para o aproveitado e o rejeitado, por período, para a pescada-foguete, a corvina e o goete, capturados pelos barcos nacionais (Fig. 7).

Para o cálculo do número de peixes rejeitados fêz-se uso das porcentagens de peixes aproveitados e rejeitados e do número de peixes desembarcados por período, e êsse número foi extrapolado para o rejeitado. Assim, por exemplo, 36\% do total de pescada- 
foguete capturado foram aproveitados e $64 \%$ foram rejeitados. Para o período de 1959 (Tabela V) foram desembarcados 6.513 .165 peixes, correspondentes aos $36 \%$. Com êsses dados calculou-se o número de peixes correspondentes aos $64 \%$, ou seja, 11.578.960 indivíduos rejeitados, que são imaturos.

Dessa maneira, para a obtenção do número total de peixes imaturos capturados pelos barcos nacionais, os peixes rejeitados foram acrescentados aos peixes imaturos aproveitados (Tabela V). $\mathrm{O}$ número de peixes maduros não variou, por não haver rejeição dêstes. Para os barcos estrangeiros o número capturado é o mesmo do aproveitado, pois não há rejeição (Tabela V).

Com os dados acima elaborou-se a Tabela VIII, onde estão lançados o número total e a relação percentual entre peixes imaturos (rejeitados e aproveitados) e maduros (aproveitados) capturados pelos barcos nacionais e estrangeiros, por período, para a pescada-foguete e a corvina (Fig. 8).

\section{III - DISCUSSÃO DOS RESULTADOS}

Primeira maturação sexual - Nas Figuras 1A, 1B, 1C e 1D observa-se o comprimento para o qual $50 \%$ dos peixes são imaturos e $50 \%$ maduros (comprimento do início da primeira maturação).

Para a sardinha-verdadeira (Fig. 1A) a primeira maturação se inicia aos $17 \mathrm{~cm}$; segundo Richardson et al. (1959) essa espécie encontra-se no segundo ano de vida com êsse comprimento.

Para a pescada-foguete (Fig. 1B) a primeira maturação se inicia aos $26 \mathrm{~cm}$ de comprimento e, segundo Lara (1951) encontra-se no terceiro ano de vida. O resultado obtido concorda com o de Lara, sendo que êste autor chegou a um valor mais baixo, por ter feito uso do comprimento padrão ("standard").

Para a corvina (Fig. 1C) a primeira maturação se inicia aos $28 \mathrm{~cm}$ de comprimento e, segundo Vazzoler (1962), encontra-se no terceiro ano de vida.

Para o goete (Fig. 1D) a primeira maturação se inicia aos $18 \mathrm{~cm}$ de comprimento, não havendo dados sôbre idade.

Nas Figuras mencionadas observa-se diferença na inclinação das curvas das espécies estudadas; assim, para a pescada-foguete e o goete as curvas apresentam pequena inclinação e, para a sardinha-verdadeira e a corvina as curvas são mais inclinadas. Êste fato sugere que o processo de maturação sexual, para a pescadafoguete e o goete, se completa num intervalo de classes de comprimento menor do que para a sardinha-verdadeira e a corvina. 
Foram considerados juntos os dois sexos, havendo possibilidade de um dêles apresentar taxa de crescimento menos elevada do que o outro e iniciar a primeira maturação com um comprimento menor. Entretanto, é nécessário um número maior de dados para se considerar os sexos em separado.

Destruição de peixes imaturos - Considerando-se o desembarcado como espécie isolada, pelos barcos nacionais, e agrupando-se todos os tipos de barcos, observa-se que:

a) para a sardinha-verdadeira (Tabela II, Fig. 2) a porcentagem de peixes imaturos desembarcados, embora tenha decrescido de ano para ano, foi alta, sendo de $43 \%$ em 1958, 32\% em 1959 e $24 \%$ em 1960. Para o total capturado essas porcentagens permaneceram constantes, por não haver rejeição de sardinha-verdadeira;

b) para a pescada-foguete(Tabela II, Fig. 2) houve um aumento na porcentagem de peixes imaturos desembarcados, sendo de $23,9 \%$ em $1958,26,1 \%$ em 1959 e $33,8 \%$ em 1960 . Observa-se ainda que o desembarcado pelas parelhinhas, em relação aos outros tipos de barcos, se manteve práticamente constante, representando, em média, para os três períodos, $21,4 \%$ do total desembarcado;

c) para a corvina (Tabela II, Fig. 2) houve um aumento da porcentagem de peixes imaturos desembarcados em 1958 e 1959 (de $29,3 \%$ para $39,7 \%$ respectivamente), decrescendo em 1960 $(26,0 \%)$. A corvina desembarcada pelas parelhinhas decresceu em 1960, representando em média, para os três períodos, $14,7 \%$ do total desembarcado;

d) para o goete (Tabela II, Fig. 2) houve um decréscimo na porcentagem de peixes imaturos desembarcados, sendo de $8,2 \%$ em 1958, 8,4\% em 1959 e 5,5\% em 1960. O desembarcado pelas parelhinhas sofreu um decréscimo de período para período, tendo representado, em média, para o três períodos, $37,7 \%$ do total desembarcado.

Considerando-se a mistura e todos os tipos de barcos nacionais agrupados, observa-se que:

a) para a pescada-foguete (Tabela III, Fig. 3) a porcentagem de peixes imaturos desembarcados foi bem elevada, tendo aumentado de um período para o outro, sendo de $68,1 \%$ em 1959 e de $98,0 \%$ em 1960, representando quase que todo o desembarcado. O desembarcado pelas parelhinhas sofreu um decréscimo, representando, entretanto, uma parcela elevada do total desembarcado: $31,3 \%$ em 1959 e $25,0 \%$ em 1960 ; 
b) para a corvina (Tabela III, Fig. 3) a porcentagem de imaturos foi muito elevada, representando quase que o total desembarcado, sendo de $91,0 \%$ em 1959 e $80,1 \%$ em 1960, ano em que houve um decréscimo. O desembarcado pelas parelhinhas sofreu uma queda acentuada, passando de 31,2\% em 1959 para $5,0 \%$ em 1960 ;

c) para o goete (Tabela III, Fig. 3) a porcentagem de imaturos foi baixa, tendo decrescido de um período para o outro, sendo de $10,9 \%$ em 1959 e 2,9\% em 1960. O desembarcado pelas parelhinhas representou uma parcela elevada do total, tendo decrescido de $1959(31,3 \%)$ para $1960(25,0 \%)$.

Para os barcos estrangeiros, considerando-se juntas as três categorias de tamanho, observa-se que:

a) para a pescada-foguete (Tabela IV, Fig. 4) a porcentagem de imaturos desembarcados permaneceu pràticamente constante nos três períodos, sendo de 41,2\% em 1958, 41,8\% em 1959 e $37,1 \%$ em 1960 . Nota-se ainda que a maior parcela do desembarcado era constituída pela categoria dos peixes médios e representou, em relação ao total, 50,1\% em 1958, 53,1\% em 1959 e $59,9 \%$ em 1960 ;

b) para a corvina (Tabela IV, Fig. 4) a porcentagem de imaturos desembarcados sofreu um ligeiro aumento, sendo de $20,9 \%$ em 1958, 26,3\% em 1959 e $26,6 \%$ em 1960 . A maior parcela do desembarcado em 1958 era constituída pela categoria de peixes médios $(83,0 \%)$ e em 1959 e 1960, pela categoria de peixes pequenos $(49,9 \%$ e $52,0 \%$ respectivamente) .

Comparando-se o número de peixes imaturos e maduros desembarcados pelos barcos nacionais e estrangeiros verifica-se que:

a) para a pescada-foguete (Tabela V, Fig. 5) o desembarcado pelos barcos estrangeiros, em relação ao total (barcos nacionais e estrangeiros) vem sofrendo um incremento de período para período, representando $50,5 \%$ em 1958, 54,5\% em 1959 e $69,9 \%$ em 1960, sendo superior à produção dos barcos nacionais. Observa-se que, em relação ao total geral desembarcado, a porcentagem de imaturos desembarcados pelos barcos nacionais vem decrescendo $(11,8 \%$ em 1958, 12,0\% em 1959 e 10,1\% em 1960), enquanto que para os barcos estrangeiros vem aumentando $(20,8 \% \mathrm{em}$ $1958,22,8 \%$ em 1959 e $25,9 \%$ em 1960).

Para o total geral desembarcado tem-se verificado um aumento na porcentagem de imaturos, sendo de $32,6 \%$ em 1958, 34,8\% em 1959 e $36,0 \%$ em 1960 ; 
b) para a corvina (Tabela V, Fig. 5) o desembarcado pelos barcos estrangeiros decresceu de 1958 para os períodos seguintes, tendo representado $62,3 \%$ em 1958, 22,4\% em 1959 e $20,4 \%$ em 1960. Isso se verificou porque, como foi dito, os barcos estrangeiros capturam quase que exclusivamente a pescada-foguete. Observa-se ainda que, em relação ao total geral desembarcado, a porcentagem de imaturos desembarcados pelos barcos nacionais sofreu um incremento (11,1\% em 1958, 39,8\% em 1959 e 38,1\% em 1960), enquanto que para os barcos estrangeiros sofreu um decréscimo (13,0\% em 1958, 5,4\% em 1959 e 5,4\% em 1960). Para o total geral desembarcado, a porcentagem de imaturos aumentou, sendo de 24,1\% em 1958, 45,7\% em 1959 e 43,5\% em 1960.

A porcentagem de peixes imaturos destruídos pelas rêdes dos barcos nacionais foi muito mais elevada do que a observada para o desembarcado, devido à parte que é rejeitada. Considerando-se a porcentagem de peixes imaturos capturados pelas parelhinhas nota-se que:

a) para a pescada-foguete (Tabela VI, Fig. 6), a porcentagem de imaturos capturados foi muito elevada, tendo sofrido um acréscimo de período para período, sendo de $72,9 \%$ em 1958 , de $73,5 \%$ em 1959 e de $76,3 \%$ em 1960 ;

b) para a corvina (Tabela VI, Fig. 6) a porcentagem de imaturos sofreu oscilação nos três períodos, mantendo-se entretanto elevada, sendo de $48,4 \%$ em $1958,68,7 \%$ em 1959 e $55,5 \%$ em 1960;

c) para o goete (Tabela VI, Fig. 6) a porcentagem de imaturos capturados foi elevada, tendo-se mantido pràticamente constante nos três períodos, sendo de 49,5\% em 1958, 48,7\% em 1959 e $47,2 \%$ em 1960 .

Para todos os tipos de barcos nacionais, considerando-se o total capturado e aplicando-se as porcentagens obtidas para o aproveitado e o rejeitado pelas parelhinhas, observa-se que:

a) para a pescada-foguete (Tabela VII, Fig. 7) a porcentagem de peixes imaturos capturados manteve-se a mesma que a observada para as parelhinhas, sendo bem elevada;

b) para a corvina (Tabela VII, Fig. 7) a porcentagem de imaturos capturados foi elevada, tendo sofrido um incremento de $1958(48,4 \%)$ para os outros dois períodos $(64,4 \%$ em 1959 e $61,9 \%$ em 1960$)$; 
c) para o goete (Tabela VII, Fig. 7) a porcentagem de peixes imaturos capturados foi elevada, tendo-se mantido pràticamente a mesma que a observada para as parelhinhas.

Comparando-se os resultados das Tabelas IV e VII nota-se que a porcentagem de imaturos capturados pelos barcos estrangeiros, para a pescada-foguete e a corvina, foi bem menor do que a observada para os barcos nacionais.

Considerando-se o total geral capturado pela frota comercial de Santos (barcos nacionais e estrangeiros) e observando-se a relação percentual entre peixes imaturos e maduros capturados observa-se que tanto para a pescada-foguete como para a corvina (Tabela VIII, Fig. 8) a porcentagem de imaturos destruídos pelas rêdes dos barcos nacionais foi muito mais elevada do que a destruída pelas dos estrangeiros, onde é pequena a porcentagem de imaturos capturados. Assim, para a pescada-foguete capturada pelos barcos nacionais tem-se 53,1\% de peixes imaturos em 1958, $51,3 \%$ em 1959 e 41,4\% em 1960 e, pelos barcos estrangeiros, $11,1 \%$ em 1958, $12,6 \%$ em 1959 e $16,9 \%$ em 1960 . Para a corvina capturada pelos barcos nacionais verificou-se a existência de $22,0 \%$ de peixes imaturos em 1958, 53,2\% em 1959 e $52,1 \%$ em 1960 e, pelos barcos estrangeiros, $11,4 \%$ em 1958, 4,6\% em 1959 e $4,2 \%$ em 1960. Isto ocorreu devido ao fato dos barcos estrangeiros usarem rêdes de malhagem grande $(68 \mathrm{~mm})$, vindo a possibilitar o escape de peixes pequenos, imaturos.

Os peixes imaturos incluídos no desembarcado não têm grande importância econômica para os pescadores, por serem pequenos, apresentando pêso individual baixo, sendo necessário um grande número para ter representação em pêso. Entretanto, essa grande destruição de peixes imaturos poderá causar variações nos estoques, uma vez que ainda não alcançaram a primeira maturação.

Êsse problema poderá ser resolvido pelo aumento da malhagem das rêdes, que possibilitará o escape de peixes pequenos, sem que isso influa, em pêso, no rendimento da pesca. Assim, de acôrdo com os dados obtidos por Richardson \& Santos (1962) calculou-se o tamanho de malha necessário para que $50 \%$ dos peixes com o comprimento do início da primeira maturação escapem das rêdes, sendo que: a) para a pescada-foguete a malha da rêde deve ser de $70 \mathrm{~mm}$; b) para a corvina, $95 \mathrm{~mm} \mathrm{e,} \mathrm{c)} \mathrm{para} \mathrm{o}$ goete, $55 \mathrm{~mm}$.

\section{IV - SUMÃRIO}

Os resultados do presente trabalho referem-se à primeira maturação sexual das espécies que apresentam maior interêsse comercial, e à destruição de peixes imaturos efetuada pelas rêdes usadas pela frota comercial de Santos (barcos nacionais e estrangeiros). 
Para a sardinha-verdadeira a primeira maturação sexual se inicia aos $17 \mathrm{~cm}$ de comprimento, no segundo ano de vida; para a pescada-foguete, aos $26 \mathrm{~cm}$ e, para a corvina, aos $28 \mathrm{~cm}$, estando ambas as espécies no terceiro ano de vida; para o goete se inicia aos $18 \mathrm{~cm}$, não havendo dados referentes à sua idade.

A inclinação das curvas sugere que o processo de maturação sexual, para a pescada-foguete e o goete, se completa num intervalo de classes de comprimeito menor do que para a sardinha-verdadeira e a corvina.

Para o desembarcado pelos barcos nacionais, como espécies isoladas, verificou-se que a porcentagem de imaturos foi elevada para a sardinha-verdadeira, a pescada-foguete e a corvina, sendo menor para o goete (Tabela II, Fig. 2). As parelhinhas desembarcaram uma pequena parcela, em relação aos outros tipos de barcos, para a pescada-foguete e a corvina, sendo que para o goete essa parcela foi elevada (Tabela II).

Com exclusão da sardinha-verdadeira, as outras três espécies são também desembarcadas pelos barcos nacionais, incluídas na mistura. Para estas observou-se que os peixes (pescada-foguete e corvina) imaturos representaram quase que o total desembarcado e, para o goete, a porcentagem de imaturos foi menos elevada (Tabela III, Fig. 3). O desembarcado pelas parelhinhas, como mistura, representou uma parcela elevada em relação aos demais tipos de barcos, para as três espécies (Tabela III).

Os barcos estrangeiros desembarcam a pescada-foguete em maior quantidade, seguida pela corvina; pode-se verificar que as porcentagens de peixes imaturos desembarcados permaneceram pràticamente constantes para a pescada-foguete, sofrendo um ligeiro aumento para a corvina (Tabela IV, Fig. 4). Os barcos estrangeiros descarregam os peixes separados em três categorias de tamanho: peixes pequenos, médios e grandes; observou-se que a maior parcela da pescada-foguete desembarcada era constituída de peixes médios e, para a corvina, de peixes médios (1958) e pequenos (1959 e 1960), conforme a mesma Tabela.

Levando-se em consideração o total geral desembarcado (barcos nacionais e estrangeiros) verificou-se que a produção dos barcos estrangeiros, em relação à dos nacionais, vem aumentando para a pescada-foguete e decrescendo para a corvina. Verificou-se ainda que a porcentagem de imaturos desembarcados aumentou de período para período, tanto para a pescadafoguete como para a corvina (Tabela V, Fig. 5).

Os barcos nacionais rejeitam grande parte do capturado, sendo que o rejeitado é constituído ùnicamente por peixes imaturos (para as espécies em estudo). Para a sardinha-verdadeira não há rejeição. Dêsse modo, para as outras três espécies, a porcentagem de imaturos capturados pelas rêdes nacionais foi muito mais elevada do que a observada para o desembarcado. Nota-se que tanto para as parelhinhas (Tabela VI, Fig. 6) como para os demais tipos de barcos (Tabela VII, Fig. 7) a porcentagem de imaturos, em relação ao total capturado (aproveitado e rejeitado), foi muito elevada para as três espécies.

Nos barcos estrangeiros, que operam com rêdes de malhagem grande $(68 \mathrm{~mm})$ não se verificou rejeição; assim, o desembarcado representou todo o capturado. Comparando-se os resultados das Tabelas IV e VII, nota-se que a porcentagem de imaturos capturados pelos barcos estrangeiros foi bem menor do que a observada para os nacionais.

Considerando-se o número total de imaturos (aproveitados e rejeitados) e maduros, capturados pelos barcos nacionais e estrangeiros, e observando-se a relação percentual entre êles, nota-se que a porcentagem de imaturos destruídos pelas rêdes nacionais foi muito mais elevada do que a verificada para as rêdes estrangeiras (Tabela VIII, Fig. 8). 
Essa grande destruição de peixes imaturos pode provocar variações nos estoques, uma vez que não alcançaram o comprimento do início da primeira maturação, não tendo, portanto, deixado descendentes.

Êsse problema poderá ser resolvido pelo aumento do tamanho das malhas das rêdes, que possibilitará o escape de peixes pequenos, sem influir no rendimento da pesca. O tamanho que as malhas deveriam ter para possibilitar o escape de $50 \%$ dos peixes com o comprimento do início da primeira maturação foi calculado, sendo: $70 \mathrm{~mm}$ para a pescada-foguete, $95 \mathrm{~mm}$ para a corvina e $55 \mathrm{~mm}$ para o goete.

\section{$\mathrm{V}$ - SUMMARY}

This paper demonstrates results obtained in studies of the size and age of first sexual maturity for some of the more important commercial species landed at Santos, and gives some information about destruction of immature fish caused by Brazilian and foreign vessels fishing from Santos.

Figures 1A, 1B, 1C and 1D indicates the length at which $50 \%$ of the fish are immature (virgins) and $50 \%$ are mature, that is, the mean length at first sexual maturity. For the sardine, it occurs at $17 \mathrm{~cm}$, in the second year; for "pescada-foguete" (weak fish) at $26 \mathrm{~cm}$ and "corvina" (with-mouth drum) at $28 \mathrm{~cm}$, both in the third year; and for "goete" (another weak fish), for which there are as yet no age data, at $18 \mathrm{~cm}$. The slopes of the curves suggest that "pescada-foguete" and "goete" mature in a interval of length classes briefer than do the other two.

The percentage of immatures landed by Brazilian vessels and sold as identified species is high for sardine, "percada-foguete" and "corvina", but low for "goete". Although the rôle of small parejas is small in the landings of the other species, it is considerable for "goete" (Table II).

With the exception of sardines, the other species are landed as "mistura" (mixed fish) by the Brazilian fishermen. Within this market category, it may be noted that almost all of the "pescada-foguete" and "corvina" are immature, although this is not true for "goete" (Table III and Fig. 3). The numbers of fish of the three species landed mixed by small parejas is lower than for other vessels, but more individuals of the three species by weight are landed by small parejas in comparison with other vessels.

Foreign boats land large amounts of "pescada-foguete" and less of "corvina". It may be seen that the percentage of immature fish remained practically constant for "pescada-foguete" but "corvina" shows a slight increase (Table IV, Fig. 4). The fish landed by the foreign boats are sorted for size, and it may be noted that "pescada-foguete" is landed almost entirely in the medium category, "corvina" as medium in 1958, but small in the latter two years.

The yield of the foreign boats, compared to the Brazilian one, shows ar: increase during the period under study in the quantities of "pescadafoguete" and a decrease for "corvina". However, the percentage of immatures landed increased for both species.

Part of the catch is discarded at sea by the Brazilian fishermen, and all of the discarded fish, so far as the three main species are concerned, are immature. No sardines are discarded. The data for small parejas, all Brazilian, show a high percentage of immatures in relation to the total caught, both landed and discarded (Table VII, Fig. 7).

On the other hand, the foreign boats, using a much larger mesh $(68 \mathrm{~mm})$, do not find it necessary to discard fish, and also, as may be seen by comparing Tables IV and VII, the percentage of immatures caught is much lower. 
It is evident that small fish caught and discarded are of no commercial value, while those landed yield little profit because of their small size. On the other hand, it is possible that large destruction of immature fish may be prejudicial to the fishery, both because they are not spared to grow to larger and more valuable sizes and because they are lost to the stocks as reproducers.

The problem posed here might be solved by an increase in the mesh size of the Brazilian vessels, giving small fish a chance to escape without very much effect on the overall yield. Fifty percent points for these species have been calculated as:

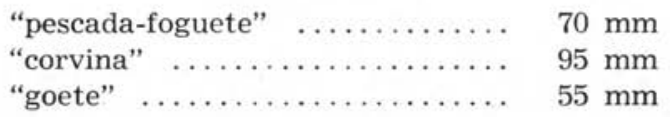

A autora agradece a orientação prestada por Mr. Ian Dennis Richardson, técnico da "Food and Agriculture Organization of the United Nations" e a todos os elementos do Grupo de Pesquisas sôbre a Pesca Marítima, que colaboraram na execução dêste trabalho.

\section{VII - BIBLIOGRAFIA}

BrAGA, A. S.

1962. Métodos de compilação e computação de dados estatísticos de desembarque de pescado no pôrto de Santos. Bol. Inst. Ocean., vol. XII, n. ${ }^{\circ}$ 2, p. 39-64.

LARA, F. J. S.

1951. A study of the life history of Macrodon ancylodon (Bloch \& Schneider), a sciaenid fish occurring on the coast of southern Brazil. An. Acad. Bras. Ci., vol. 23, n. ${ }^{\circ}$ 3, p. 291-322.

MOREIRA, P. S.

Quantidade dos peixes rejeitados pela frota comercial de Santos e observações sôbre a seletividade de malhas de $54 \mathrm{~mm}$. (Em preparação).

Nomura, H.

1960. Considerações sôbre amostragem de peixes marinhos (I). Bol. Inst. Ocean., vol. XI, n. ${ }^{\circ}$, p. 99-120.

Richardson, I. D. \& Santos, E. P.

Note on the selectivity of meshes used by the Santos fishing fleet. Bol. Inst. Ocean., vol. XII, n. ${ }^{\circ} 1$, p. 33-52, figs. tabs.

Richardson, I. D., Vazzoler, G., Faria, A. \& Moraes, M. N.

1959. Report on sardine investigations in Brazil. FAO, Rome, $\mathrm{v}+7$ p., figs. tabs. (Experience paper, n. ${ }^{\circ} 13$ ).

VAZZOLER, G.

1962. Sôbre a biologia da corvina da costa sul do Brasil. Bol Inst. Ocean., vol. XII, n. ${ }^{\circ}$, p. 53-102, figs. tabs. 
TABELA IA - SARdiNHA - Distribuição dos grupos de maturidade, por classe de comprimento

\begin{tabular}{|c|r|r|r|r|}
\hline \multirow{2}{*}{$\begin{array}{c}\text { COMPRIMENTO } \\
\text { ( C M ) }\end{array}$} & \multicolumn{2}{|c|}{ VIRGENS } & \multicolumn{2}{c|}{ MADUROS } \\
\cline { 2 - 5 } & Ne & $\%$ & N & \multicolumn{1}{c|}{$\%$} \\
\hline 11,5 & 1 & 100,00 & - & 0 \\
12,5 & 28 & 100,00 & - & 0 \\
13,5 & 39 & 100,00 & - & 0 \\
14,5 & 63 & 98,40 & 1 & 1,56 \\
15,5 & 147 & 92,90 & 11 & 6,95 \\
16,5 & 200 & 64,80 & 108 & 34,99 \\
17,5 & 307 & 38,68 & 486 & 61,23 \\
18,5 & 346 & 33,87 & 675 & 66,08 \\
19,5 & 214 & 22,90 & 720 & 77,04 \\
20,5 & 121 & 16,45 & 611 & 83,09 \\
21,5 & 53 & 11,81 & 394 & 87,86 \\
22,5 & 25 & 5,50 & 429 & 94,38 \\
23,5 & 7 & 2,43 & 281 & 97,50 \\
24,5 & 1 & 1,31 & 75 & 98,62 \\
25,5 & - & 0 & 6 & 100,00 \\
\hline T O T A L & 1552 & - & 3797 & - \\
\hline
\end{tabular}




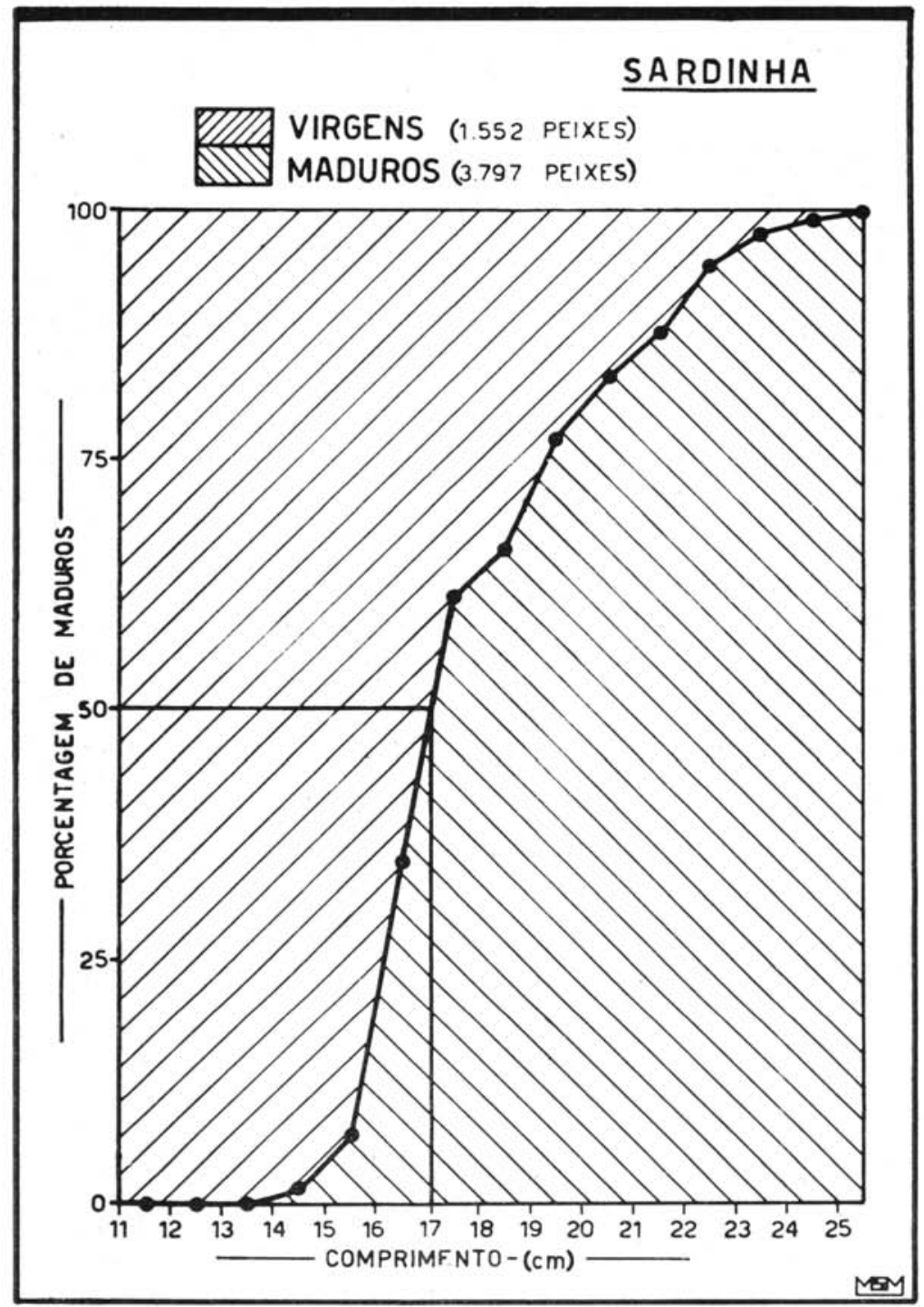

Fig. 1A - Distribuição por classe de comprimento, das freqüências de peixes maduros, para a saldinha-verdadeira. 
TABELA IB - PescadA-Foguete - Distribuição dos grupos de maturidade, por classe de comprimento

\begin{tabular}{|c|c|c|c|c|}
\hline \multirow{2}{*}{$\begin{array}{c}\text { COMPRIMENTO } \\
(\mathrm{C} M)\end{array}$} & \multicolumn{2}{|c|}{ VIRGENS } & \multicolumn{2}{|c|}{ MADUROS } \\
\hline & Ne & $\%$ & Ne & $\%$ \\
\hline 15,5 & 3 & 100,00 & - & 0 \\
\hline 16,5 & 2 & 100,00 & - & 0 \\
\hline 17,5 & 13 & 100,00 & - & 0 \\
\hline 18,5 & 29 & 100,00 & - & 0 \\
\hline 19,5 & 43 & 97,61 & 1 & 2,27 \\
\hline 20,5 & 73 & 95,63 & 3 & 3,93 \\
\hline 21,5 & 51 & 82,11 & 11 & 17,71 \\
\hline 22,5 & 61 & 73,20 & 22 & 26,40 \\
\hline 23,5 & 78 & 65,30 & 40 & 34,00 \\
\hline 24,5 & 69 & 56,58 & 52 & 42,64 \\
\hline 25,5 & 63 & 51,66 & 58 & 47,56 \\
\hline 26,5 & 38 & 36,86 & 65 & 63,05 \\
\hline 27,5 & 34 & 27,54 & 89 & 72,09 \\
\hline 28,5 & 22 & 21,34 & 81 & 78,57 \\
\hline 29,5 & 11 & 8,69 & 116 & 91,64 \\
\hline 30,5 & 7 & 6,44 & 101 & 92,92 \\
\hline 31,5 & 5 & 4,30 & 111 & 95,46 \\
\hline 32,5 & - & 0 & 107 & 100,00 \\
\hline 33,5 & - & 0 & 86 & 100,00 \\
\hline 34,5 & - & 0 & 85 & 100,00 \\
\hline 35,5 & - & 0 & 63 & 100,00 \\
\hline 36,5 & - & 0 & 55 & 100,00 \\
\hline 37,5 & - & 0 & 41 & 100,00 \\
\hline 38,5 & - & 0 & 23 & 100,00 \\
\hline 39,5 & - & 0 & 18 & 100,00 \\
\hline 40,5 & - & 0 & 12 & 100,00 \\
\hline 41,5 & - & 0 & 1 & 100,00 \\
\hline 42,5 & - & 0 & 4 & 100,00 \\
\hline TO T A I & 602 & - & 1.245 & - \\
\hline
\end{tabular}




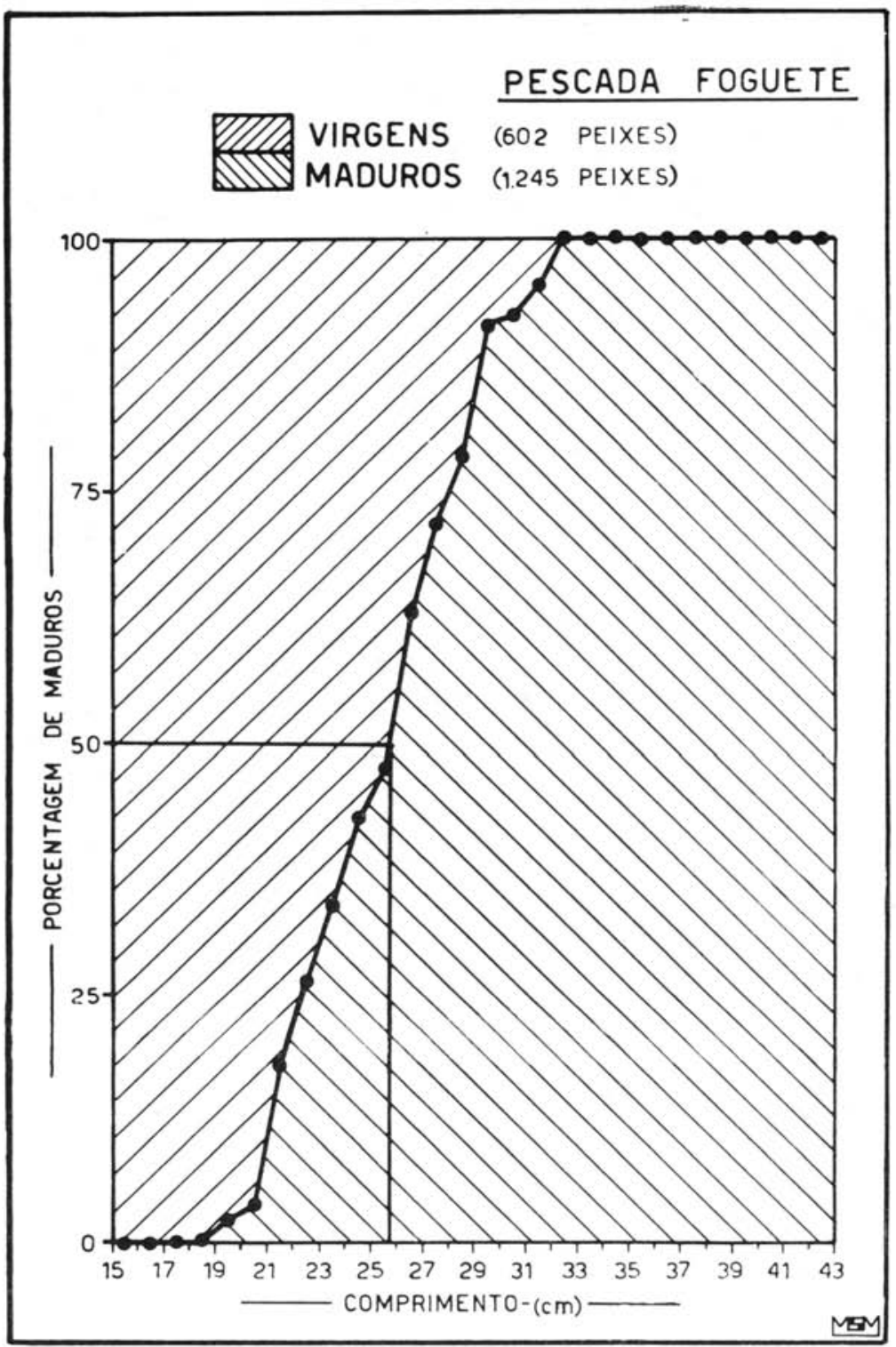

Fig. 1B - Distribuição por classe de comprimento, das freqüências de peixes maduros, para a pescada-foguete. 
TABELA IC - CoRvina - Distribuição dos grupos de maturidade, por classe de comprimento

\begin{tabular}{|c|c|c|c|c|}
\hline \multirow{2}{*}{$\begin{array}{l}\text { COMPRIMENTO } \\
(C M)\end{array}$} & \multicolumn{2}{|c|}{ VIRGENS } & \multicolumn{2}{|c|}{ MADUROS } \\
\hline & $\mathrm{Ne}$ & $\%$ & No & $\%$ \\
\hline 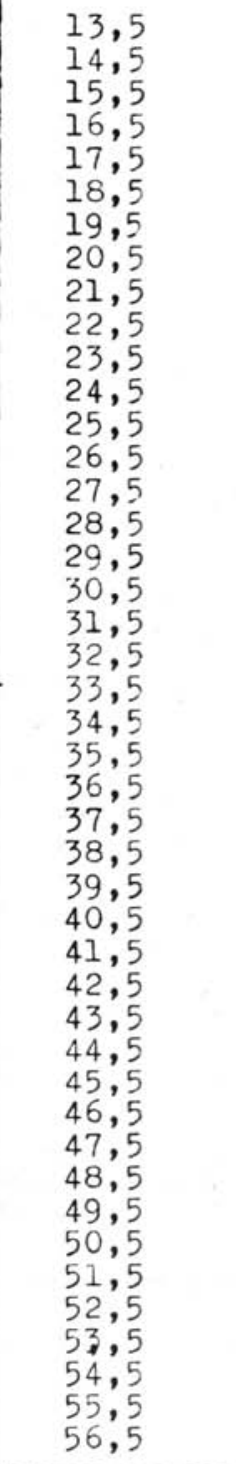 & $\begin{array}{l}1 \\
1 \\
1 \\
3 \\
6 \\
6 \\
3 \\
16 \\
20 \\
15 \\
19 \\
15 \\
20 \\
13 \\
26 \\
12 \\
11 \\
16 \\
16 \\
11 \\
12 \\
11 \\
5 \\
2 \\
- \\
- \\
- \\
- \\
- \\
- \\
- \\
- \\
- \\
- \\
- \\
- \\
- \\
- \\
- \\
- \\
-\end{array}$ & $\begin{array}{l}100,00 \\
100,00 \\
100,00 \\
100,00 \\
100,00 \\
100,00 \\
100,00 \\
100,00 \\
100,00 \\
100,00 \\
86,26 \\
68,10 \\
76,80 \\
54,08 \\
52,00 \\
26,64 \\
22,44 \\
28,48 \\
33,28 \\
19,58 \\
22,56 \\
24,42 \\
11,60 \\
7,68 \\
0 \\
0 \\
0 \\
0 \\
0 \\
0 \\
0 \\
0 \\
0 \\
0 \\
0 \\
0 \\
0 \\
0 \\
0 \\
0 \\
0 \\
0 \\
0 \\
0 \\
5\end{array}$ & $\begin{array}{l}- \\
- \\
- \\
- \\
- \\
- \\
- \\
- \\
- \\
- \\
3 \\
7 \\
6 \\
11 \\
24 \\
33 \\
38 \\
40 \\
32 \\
45 \\
41 \\
34 \\
38 \\
24 \\
24 \\
20 \\
25 \\
19 \\
14 \\
16 \\
16 \\
11 \\
7 \\
12 \\
10 \\
7 \\
7 \\
12 \\
7 \\
7 \\
8 \\
7 \\
5 \\
2\end{array}$ & $\begin{array}{c}0 \\
0 \\
0 \\
0 \\
0 \\
0 \\
0 \\
0 \\
0 \\
0 \\
13,02 \\
31,78 \\
23,04 \\
45,76 \\
48,00 \\
73,26 \\
77,52 \\
71,20 \\
66,56 \\
80,10 \\
77,08 \\
75,48 \\
88,16 \\
92,16 \\
100,00 \\
100,00 \\
100,00 \\
100,00 \\
100,00 \\
100,00 \\
100,00 \\
100,00 \\
100,00 \\
100,00 \\
100,00 \\
100,00 \\
100,00 \\
100,00 \\
100,00 \\
100,00 \\
100,00 \\
100,00 \\
100,00 \\
100,00\end{array}$ \\
\hline $\mathrm{T} O \mathrm{TA} \mathrm{A}$ & 261 & - & 612 & - \\
\hline
\end{tabular}




\section{CORVINA}

VIRGENS (251 PEIXES) MADUROS (612 PEIXES)

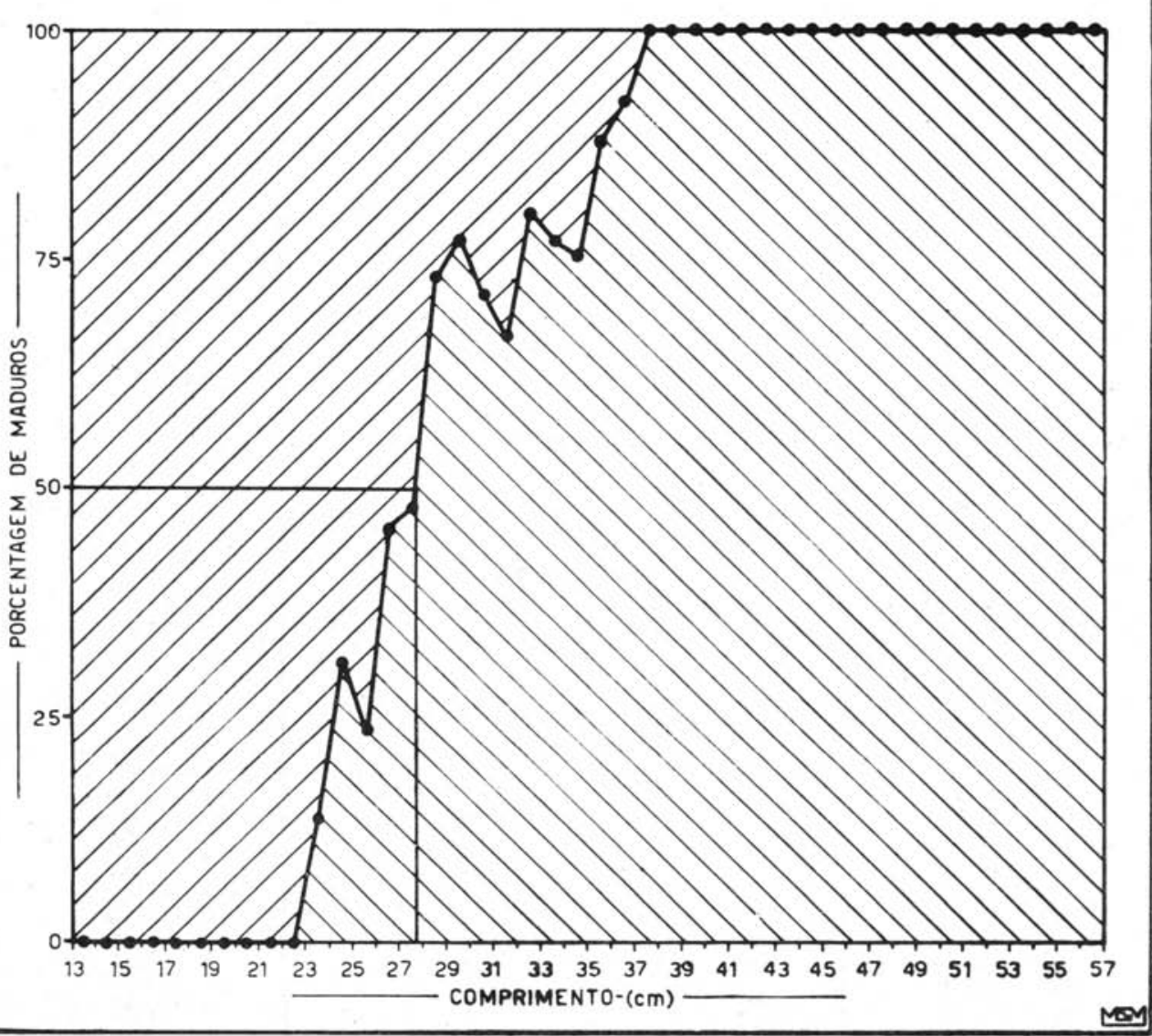

Fig. 1C - Distribuição por classe de comprimento, das frequêencias de peixes maduros, para a corvina. 
TABELA ID - Goete - Distribuição dos grupos de maturidade, por classe de comprimento

\begin{tabular}{|c|c|c|c|c|}
\hline \multirow{2}{*}{$\begin{array}{c}\text { COMPRIMENTO } \\
(\text { C M ) }\end{array}$} & \multicolumn{2}{|c|}{ VIRGENS } & \multicolumn{2}{|c|}{ MADUROS } \\
\hline & Ne & $\%$ & Ne & $\not$ \\
\hline 13,5 & 2 & 100,00 & - & 0 \\
\hline 14,5 & 7 & 100,00 & - & 0 \\
\hline 15,5 & 14 & 100,00 & - & 0 \\
\hline 16,5 & 17 & 68,00 & 8 & 32,00 \\
\hline 17,5 & 28 & 60,84 & 18 & 39,11 \\
\hline 18,5 & 20 & 25,96 & 57 & 73,98 \\
\hline 19,5 & 19 & 18,43 & 84 & 81,48 \\
\hline 20,5 & 9 & 7,08 & 118 & 92,86 \\
\hline 21,5 & 5 & 3,31 & 146 & 96,65 \\
\hline 22,5 & 1 & $=0,80$ & 124 & 99,20 \\
\hline 23,5 & 1 & 0,68 & 146 & 99,28 \\
\hline 24,5 & 1 & 0,79 & 125 & 99,12 \\
\hline 25,5 & 1 & 0,82 & 120 & 93,12 \\
\hline 26,5 & - & 0 & 99 & 100,00 \\
\hline 27,5 & - & 0 & 51 & 100,00 \\
\hline 28,5 & - & 0 & 24 & 100,00 \\
\hline 29,5 & - & 0 & 17 & 100,00 \\
\hline 30,5 & - & 0 & 7 & 100,00 \\
\hline 31,5 & - & 0 & 9 & 100,00 \\
\hline 32,5 & - & 0 & 2 & 100,00 \\
\hline $\mathrm{T} O \mathrm{TAL}$ & 125 & - & 1155 & - \\
\hline
\end{tabular}




VIRGENS (125 PEIXES)
MADUROS (1.155

GOETE

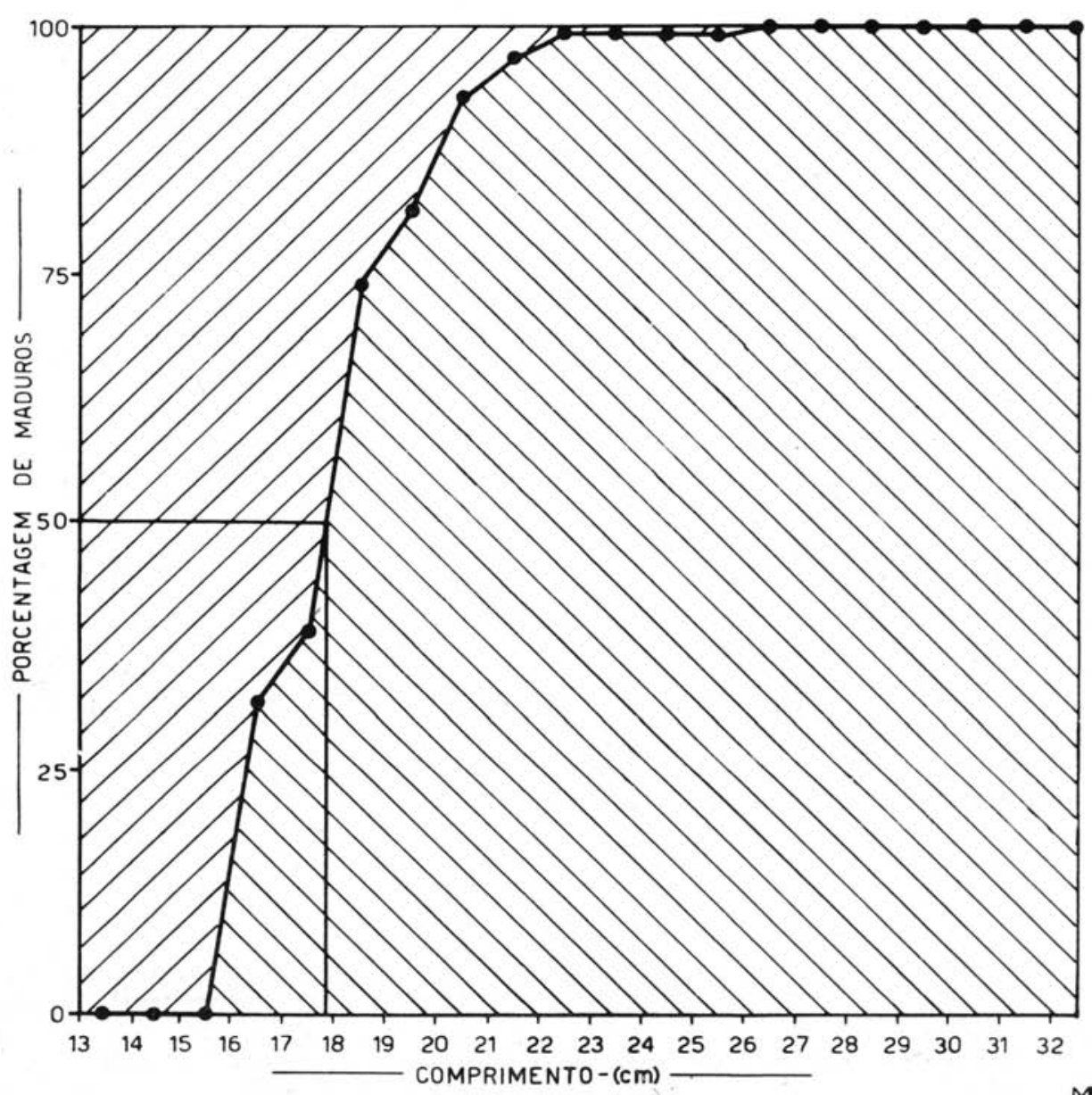

Fig. 1D - Distribuição por classe de comprimento, das freqüências de peixes maduros, para o goete. 


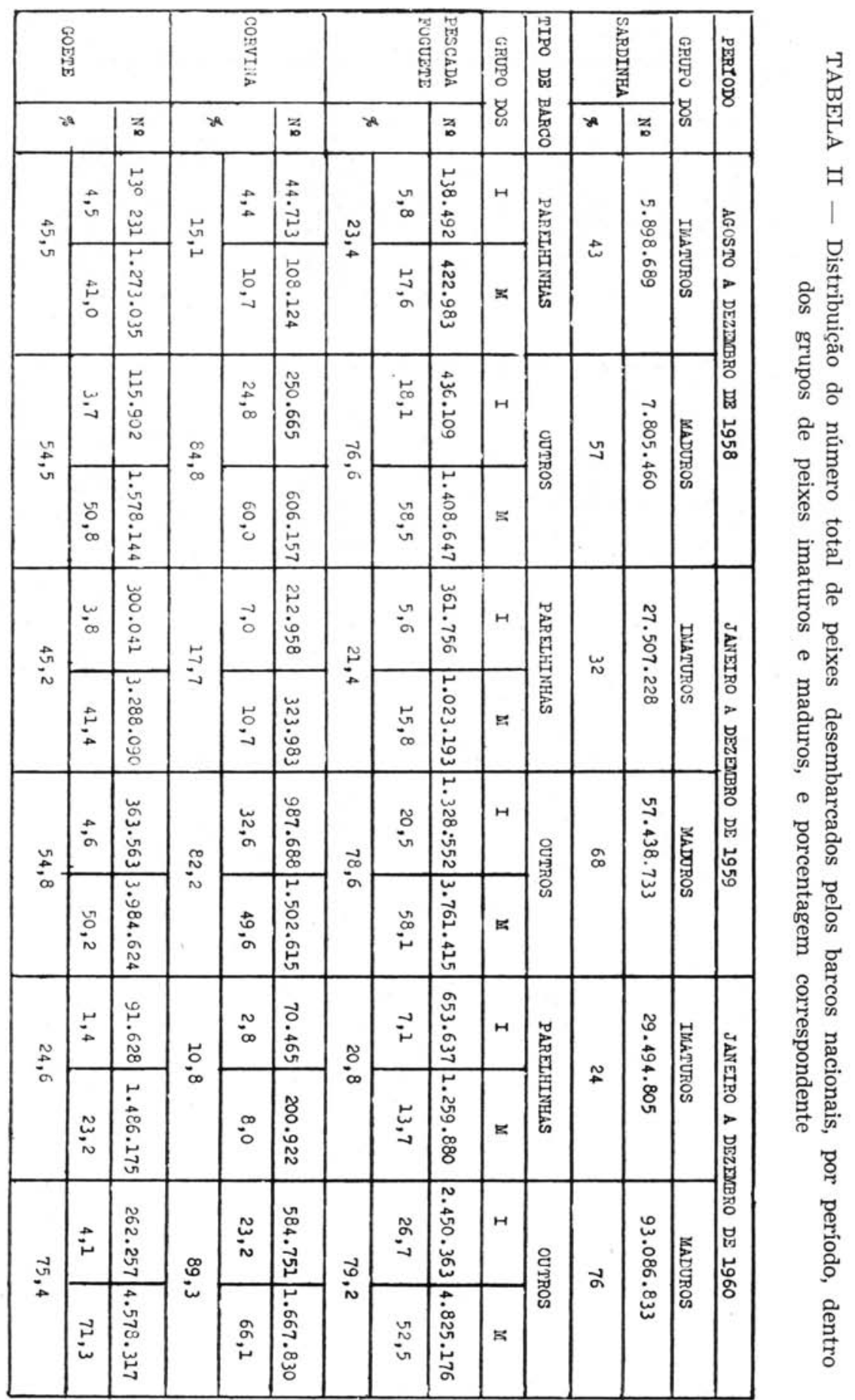




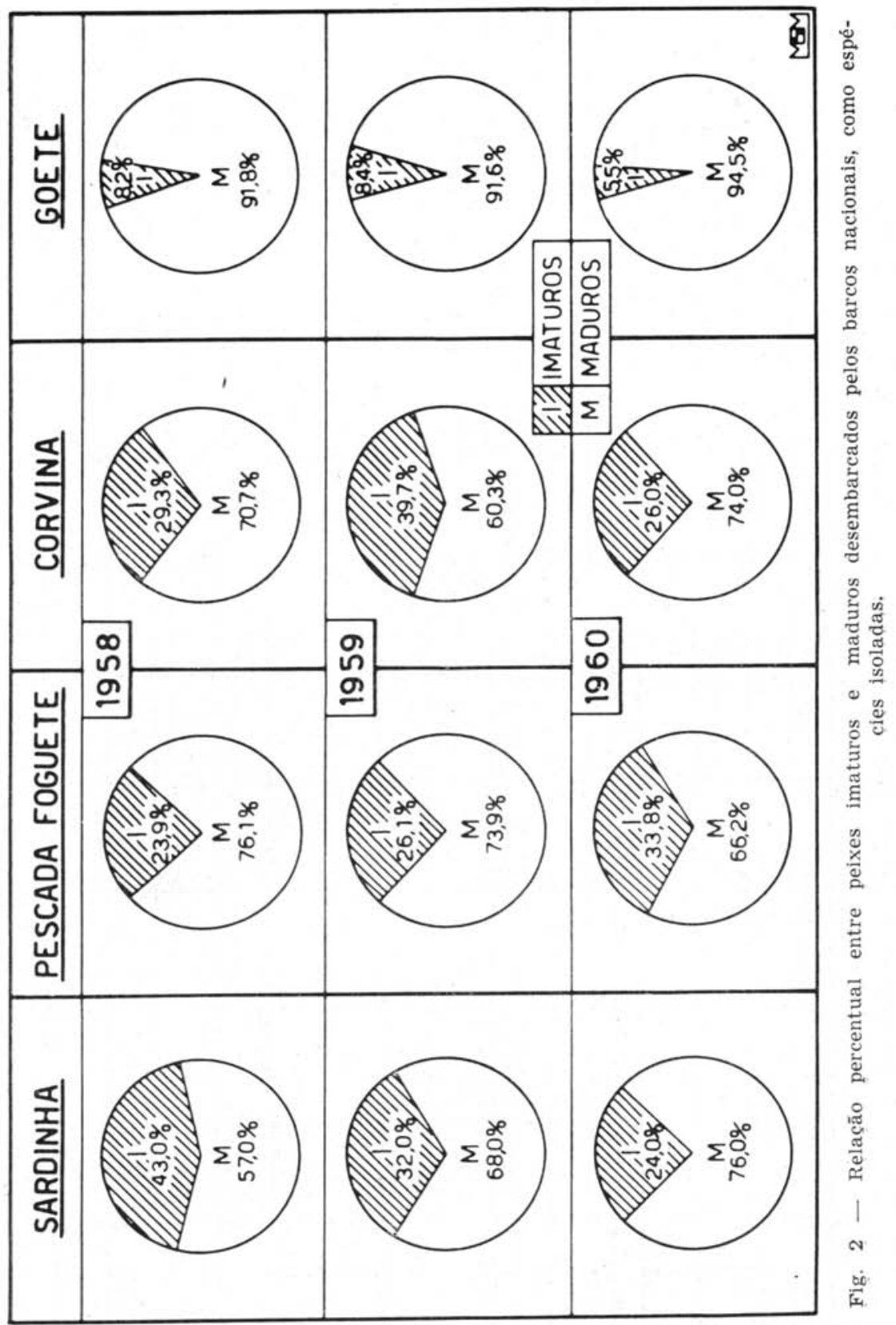


TABELA III - Distribuição do número total de peixes desembarcados pelos barcos nacionais, incluídos na mistura, por período, dentro dos grupos de peixes imaturos (I) e maduros (M), e porcentagem correspondente

\begin{tabular}{|c|c|c|c|c|c|c|c|c|c|}
\hline \multicolumn{2}{|c|}{ PERIODO } & \multicolumn{4}{|c|}{ JANEIRO A DEZEMBRO DE 1959} & \multicolumn{4}{|c|}{ JANBIRO A DEZEMBRO DE 1960} \\
\hline \multicolumn{2}{|c|}{ TIPO DE BARCO } & \multicolumn{2}{|c|}{ PARELHINHAS } & \multicolumn{2}{|c|}{ OUTROS } & \multicolumn{2}{|c|}{ PARELHINHAS } & \multicolumn{2}{|c|}{ OUTROS } \\
\hline \multicolumn{2}{|c|}{ GRUPO DOS } & I & M & I & $M$ & I & M & I & in \\
\hline \multirow{3}{*}{$\begin{array}{l}\text { PESCADA } \\
\text { FOGUETE }\end{array}$} & $\mathrm{Ne}$ & 8.151 & 3.821 & 17.888 & 8.389 & 530 & 11 & 1.592 & 32 \\
\hline & \multirow{2}{*}{$x$} & 21,3 & 10,0 & 46,8 & 21,9 & 24,5 & 0,5 & 73,5 & 1,5 \\
\hline & & \multicolumn{2}{|c|}{31,3} & \multicolumn{2}{|c|}{68,7} & \multicolumn{2}{|c|}{$<5,0$} & \multicolumn{2}{|c|}{75,0} \\
\hline \multirow{3}{*}{ CORVINA } & $\mathrm{Ne}$ & 250.455 & 24.642 & 550.449 & 54.262 & 68.745 & 17.022 & 1.299 .208 & 321.695 \\
\hline & \multirow{2}{*}{ 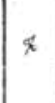 } & 28,4 & 2,8 & 62,6 & 6,2 & 4,0 & 1,0 & 76,1 & 18,9 \\
\hline & & \multicolumn{2}{|c|}{32,2} & \multicolumn{2}{|c|}{68,8} & \multicolumn{2}{|c|}{5,0} & \multicolumn{2}{|c|}{95,0} \\
\hline \multirow{3}{*}{ GOETE } & ine & 6.433 & 52.573 & 14.116 & 115.363 & 202 & 6.864 & 605 & 20.549 \\
\hline & \multirow{2}{*}{$\%$} & 3,4 & 27,9 & 7,5 & 61,2 & 0,7 & 24,3 & 2,2 & 72,8 \\
\hline & & \multicolumn{2}{|c|}{31,3} & \multicolumn{2}{|c|}{68,7} & \multicolumn{2}{|c|}{25,0} & \multicolumn{2}{|c|}{75,0} \\
\hline
\end{tabular}




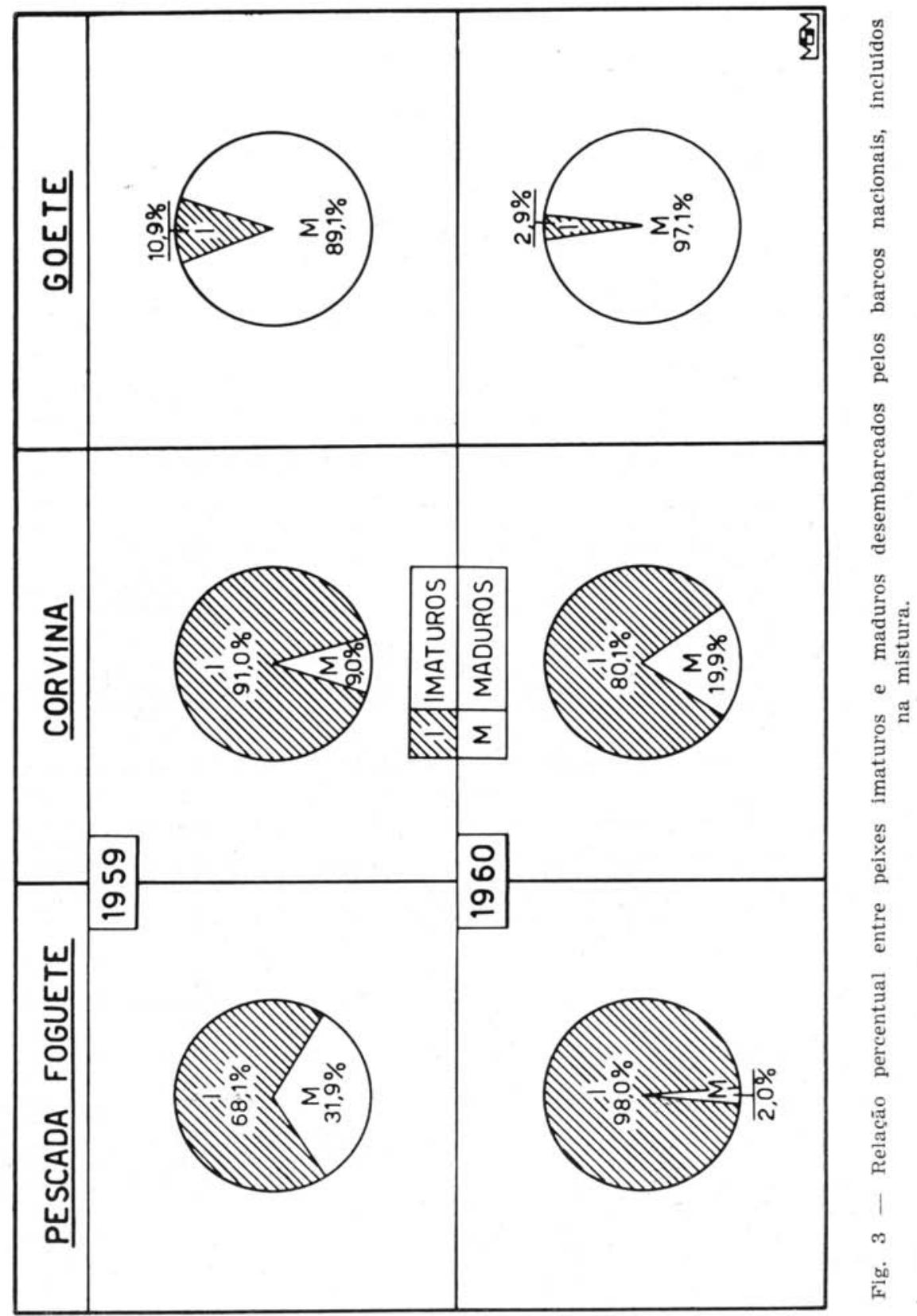




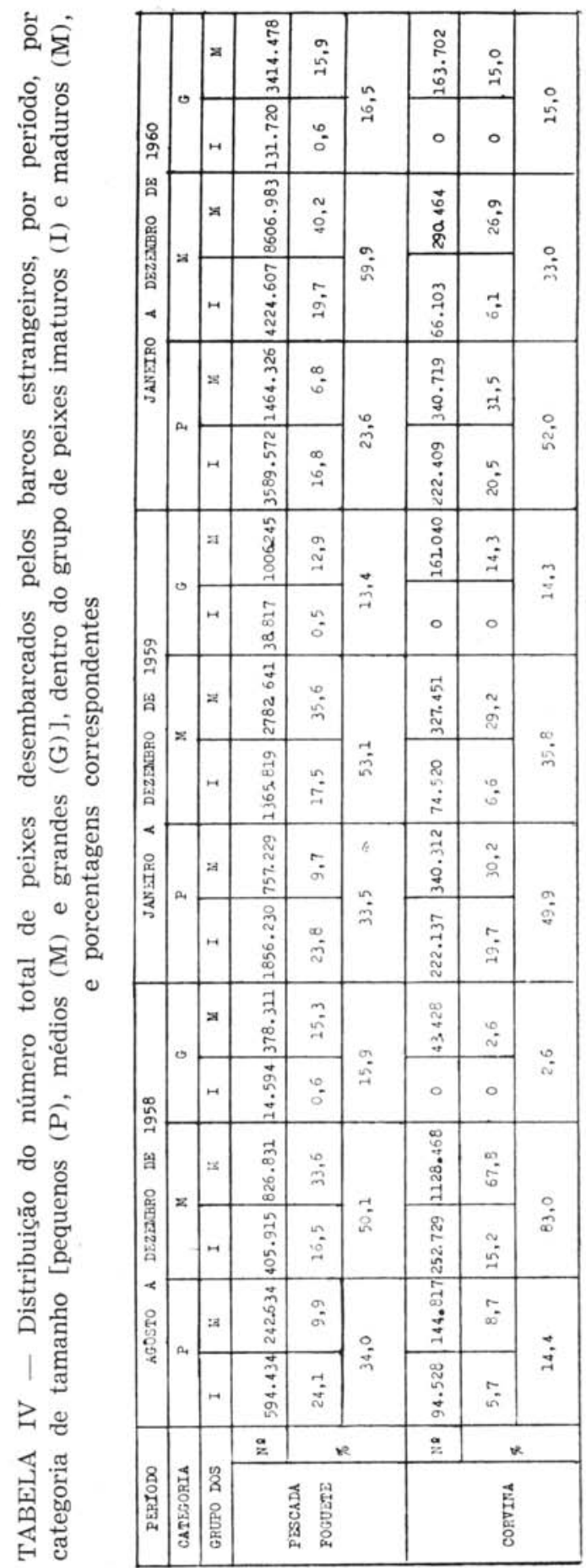




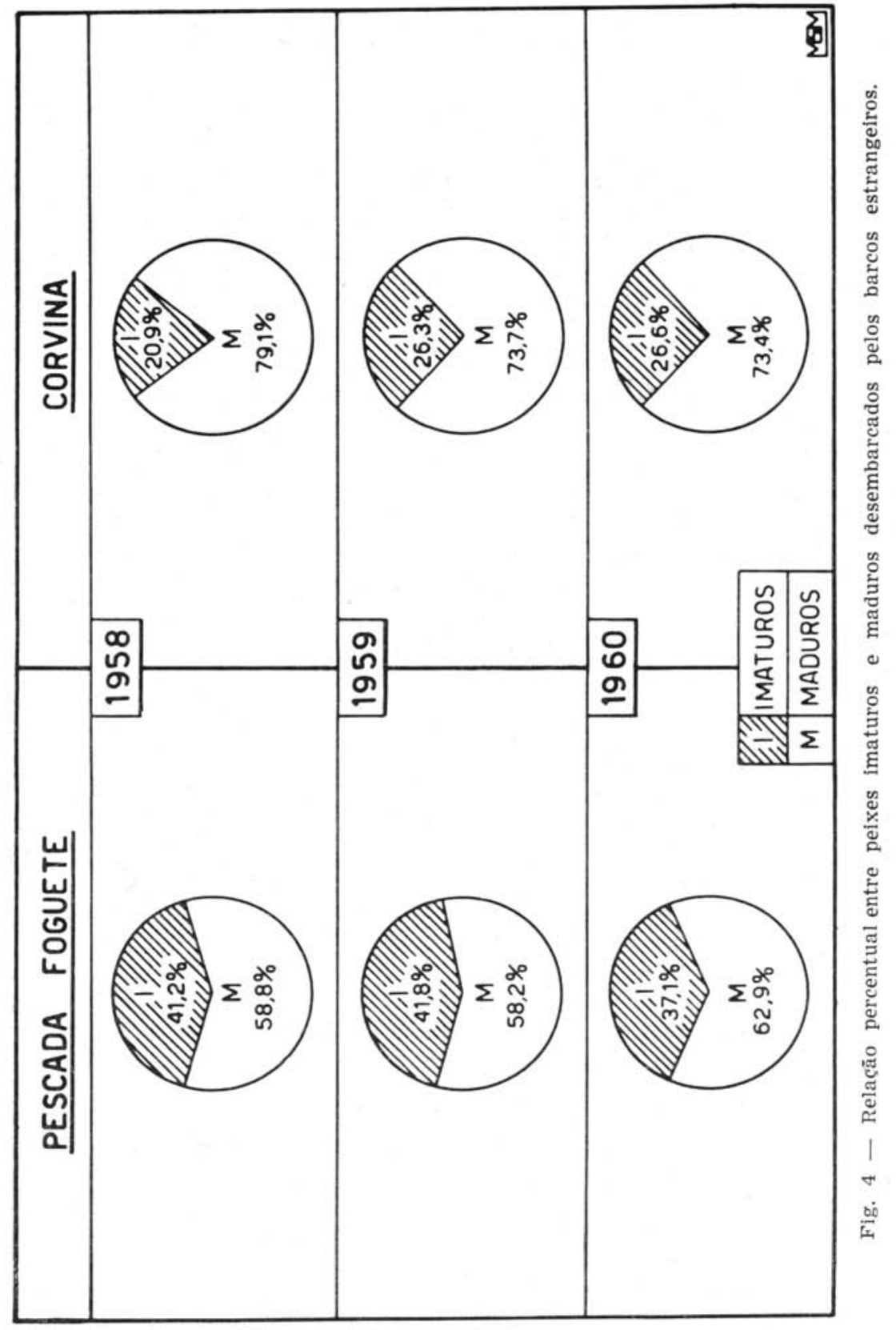




\begin{tabular}{|c|c|c|c|c|c|c|c|c|c|c|c|c|c|c|c|}
\hline 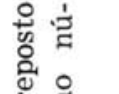 & & 8 & & ve & क् & $\stackrel{9}{8}$ & m & & 응 & & & 8 & ๓n & 음 & แn \\
\hline E్ & & जิ & & be & $\stackrel{-1}{\circ}$ & 亲 & $\stackrel{0}{\circ}$ & & 拿 & & & 8 & 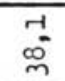 & in & $\stackrel{n}{m}$ \\
\hline 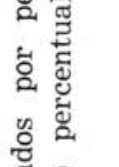 & & 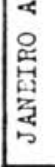 & 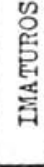 & $\stackrel{\circ}{\stackrel{1}{z}}$ & $\begin{array}{l}\tilde{N} \\
\stackrel{-1}{0} \\
\stackrel{\overbrace{}}{\nearrow} \\
\dot{n}\end{array}$ & 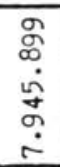 & 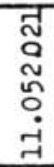 & & 点 & 瓷 & 일 & $\frac{d}{2}$ & $\begin{array}{l}\text { gु } \\
\stackrel{-1}{0} \\
\dot{\sim} \\
0 \\
\dot{\sim}\end{array}$ & 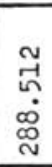 & 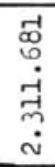 \\
\hline ల్లే & & 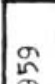 & & $E^{2}$ & $\stackrel{n}{m}$ & సं & $\stackrel{\sim}{n}$ & & ్ㅛ & & 8 & or & gr & ñ & $\stackrel{+}{\dot{*}}$ \\
\hline 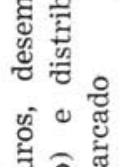 & 舅 & $\begin{array}{l}\text { 年 } \\
\text { 留 } \\
\text { 足 } \\
\text { 窟 }\end{array}$ & 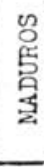 & 兑 & 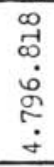 & 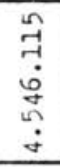 & $\begin{array}{l}m \\
\tilde{m} \\
\dot{\sim} \\
\tilde{m} \\
\dot{\sigma}\end{array}$ & & 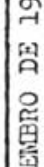 & 瓷 & $\stackrel{\alpha}{z}$ & $\frac{\alpha}{z}$ & $\begin{array}{l}\text { N } \\
\text { in } \\
\text { n } \\
\text { ᄋ̆ } \\
\text { ri }\end{array}$ & $\begin{array}{l}\text { m } \\
\infty \\
\stackrel{\sim}{\infty} \\
\infty\end{array}$ & 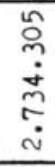 \\
\hline 胥 & $\mathrm{Fen}$ & 筫 & & re & $\stackrel{0}{2}$ & $\stackrel{\infty}{N}$ & $\stackrel{\infty}{\dot{m}}$ & & 哈 & & & R & in & of & ก \\
\hline 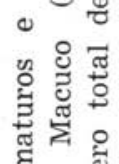 & 帘 & 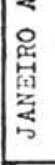 & 㬅 & $\underset{z}{a}$ & 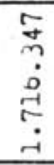 & $\begin{array}{l}\mathscr{L} \\
\infty \\
\dot{0} \\
\stackrel{\mathscr{L}}{\sim} \\
\dot{n}\end{array}$ & $\begin{array}{l}\frac{m}{\pi} \\
\stackrel{2}{\pi} \\
\dot{0}\end{array}$ & 竞 & 䍃 & 梁 & & $\frac{a}{z}$ & $\begin{array}{l}\text { 유 } \\
\text { م- } \\
\text { రั } \\
\dot{\sim}\end{array}$ & 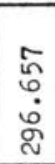 & 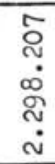 \\
\hline 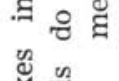 & 臽 & $\infty$ & & 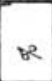 & $\stackrel{0}{m}$ & ì & $\frac{\pi}{6}$ & & $\infty$ & & & 2 & $\stackrel{0}{2}$ & m & $\underset{1}{2}$ \\
\hline లే & & 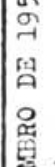 & 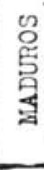 & $\stackrel{a}{z}$ & 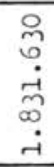 & 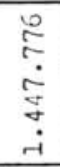 & 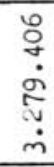 & & 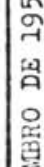 & 瓷 & & 은 & 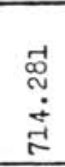 & $\begin{array}{l}m \\
\vec{T} \\
\dot{T} \\
-1 \\
\dot{-1} \\
\dot{H}\end{array}$ & 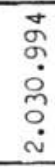 \\
\hline 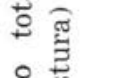 & & 空 & & ve & $\underset{-1}{-i}$ & $\infty$ & $\begin{array}{l}0 \\
\stackrel{m}{m}\end{array}$ & & 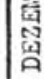 & & & $\mathrm{B}$ & ન્- & $\stackrel{0}{n}$ & $\stackrel{-1}{d}$ \\
\hline है & & 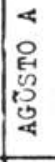 & 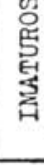 & $\stackrel{a}{z}$ & $\begin{array}{l}-1 \\
\text { S } \\
\dot{0} \\
\end{array}$ & 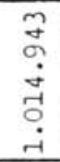 & 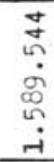 & & $\begin{array}{l}4 \\
0 \\
\text { 버 } \\
0 \\
0 \\
0 \\
4\end{array}$ & 窇 & & $\cong$ & 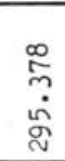 & 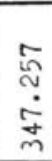 & $\begin{array}{l}\stackrel{n}{0} \\
0 \\
\dot{v} \\
\dot{v}\end{array}$ \\
\hline : & 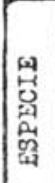 & 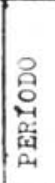 & 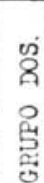 & & 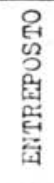 & 导 & 롫 & $\begin{array}{l}\text { 兽 } \\
\text { 畣 } \\
\text { 急 }\end{array}$ & 总 & 号 & & & 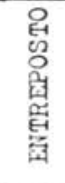 & 융 & 丞 \\
\hline
\end{tabular}




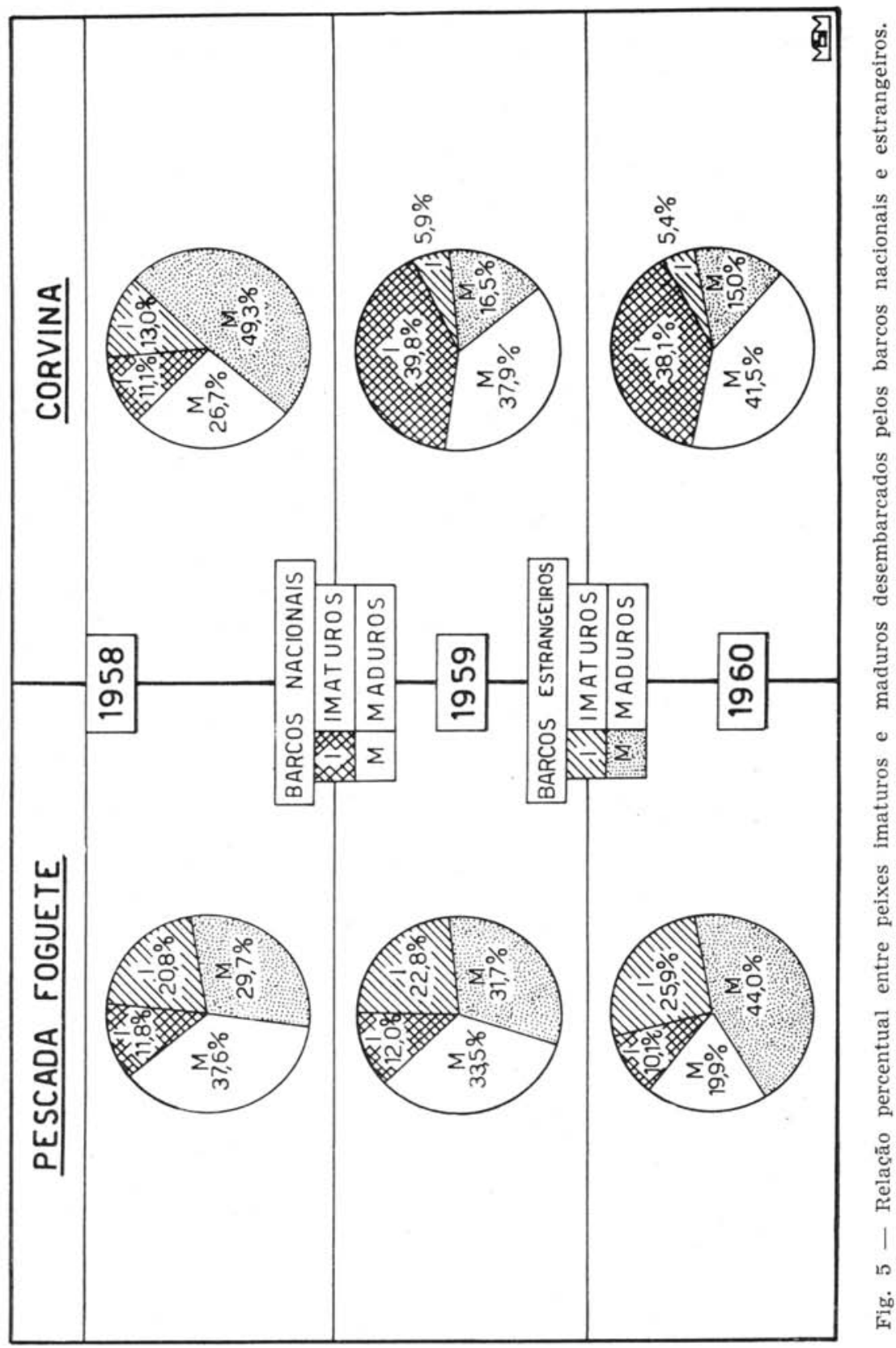




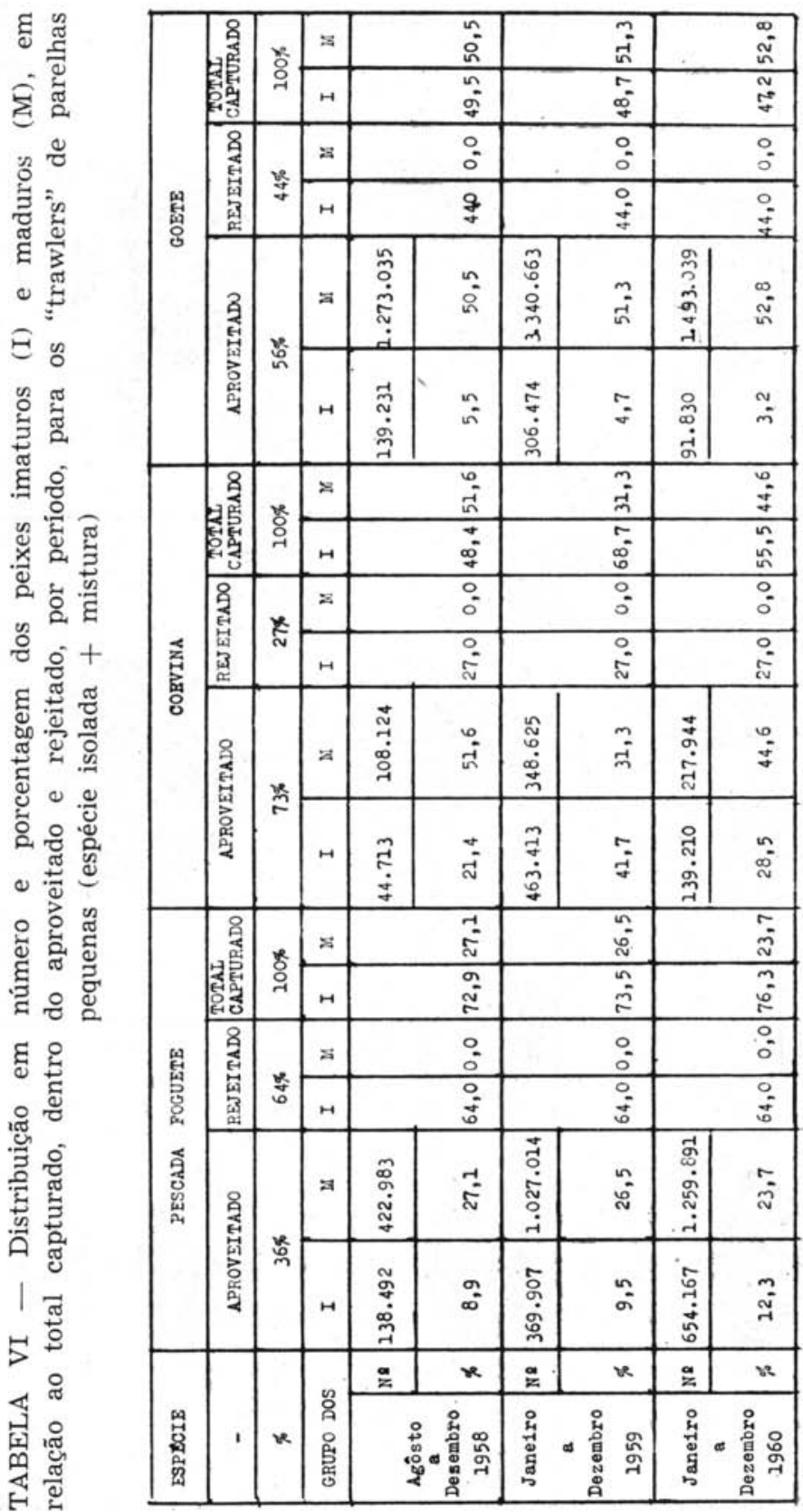




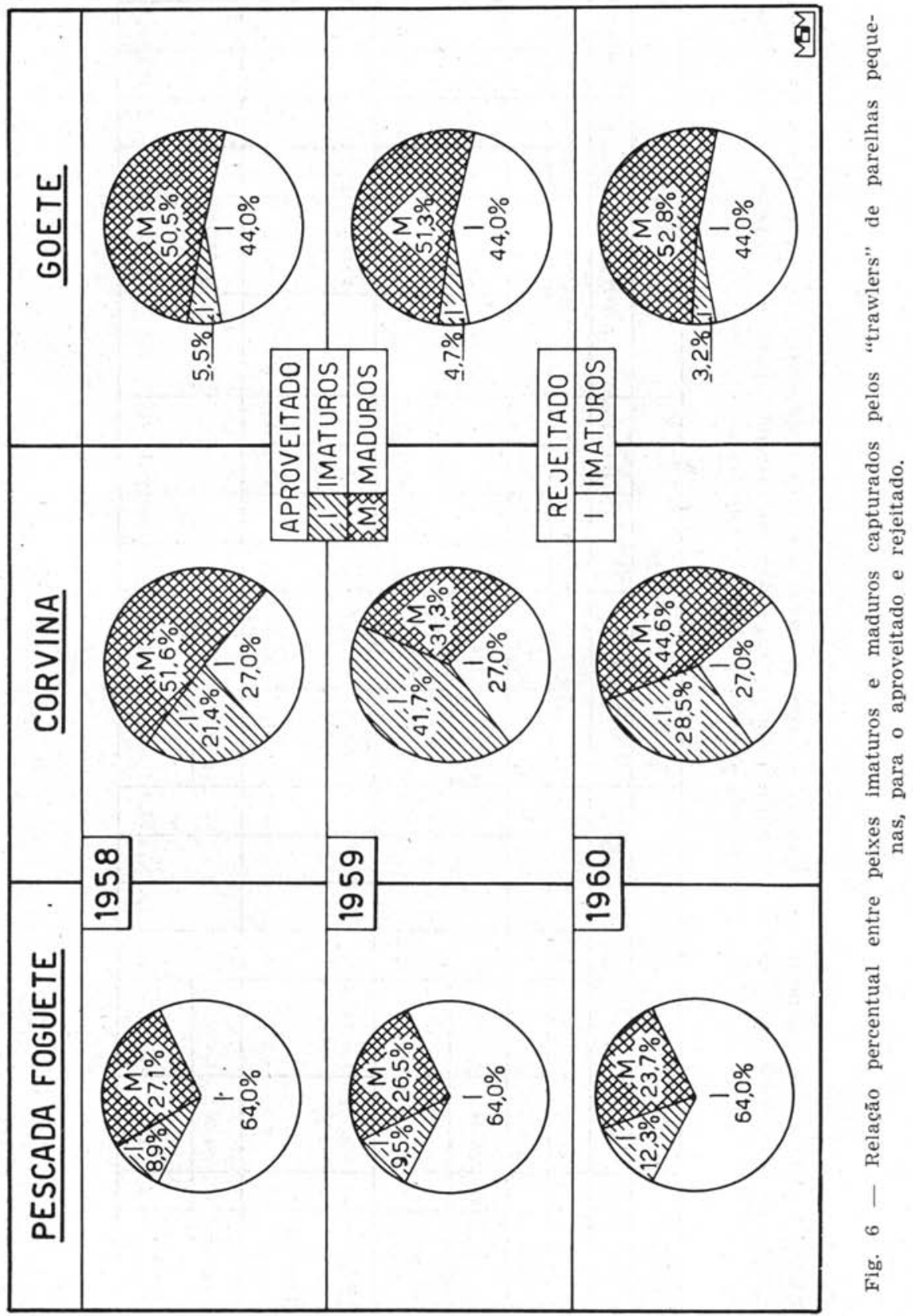




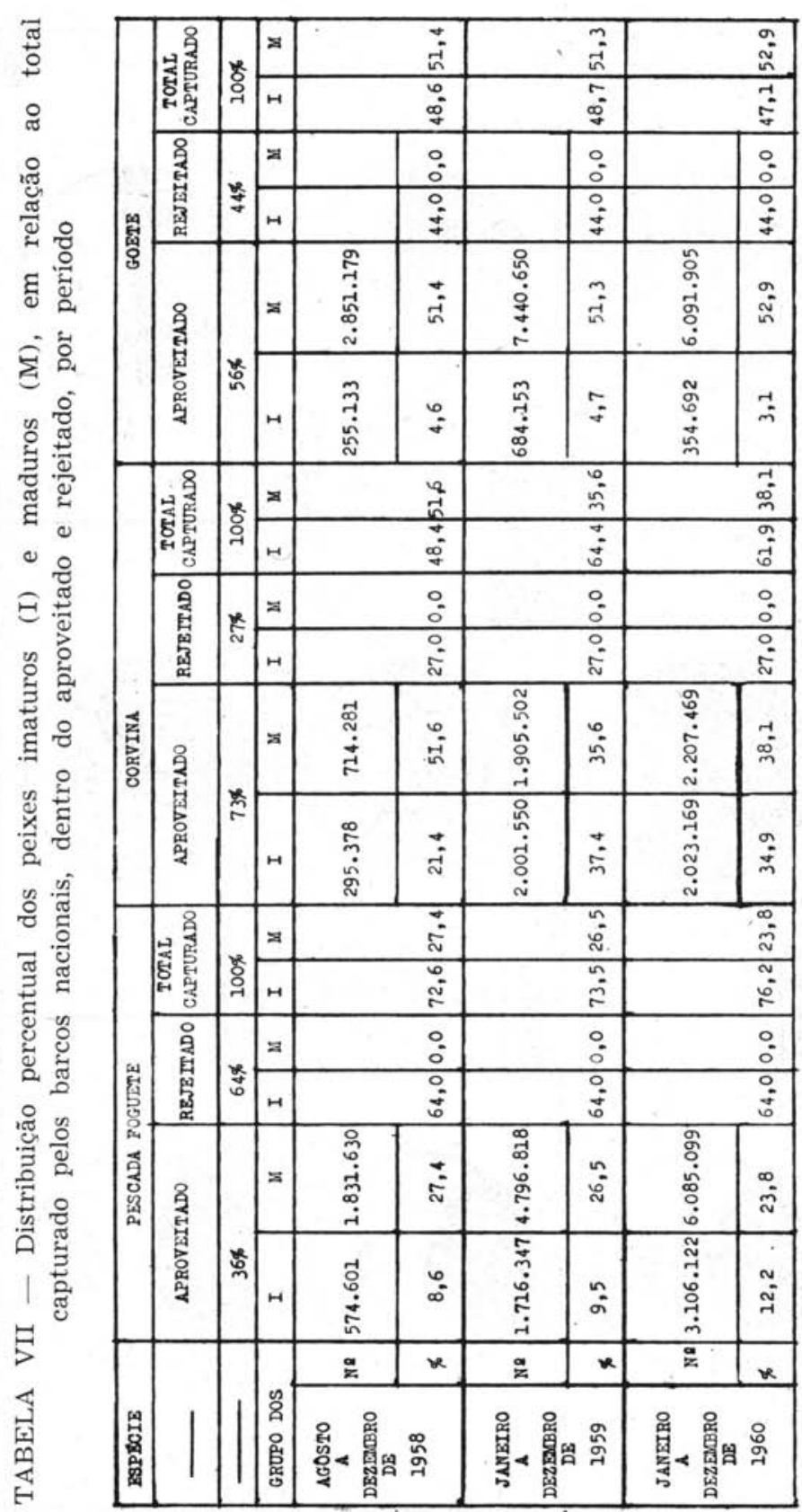




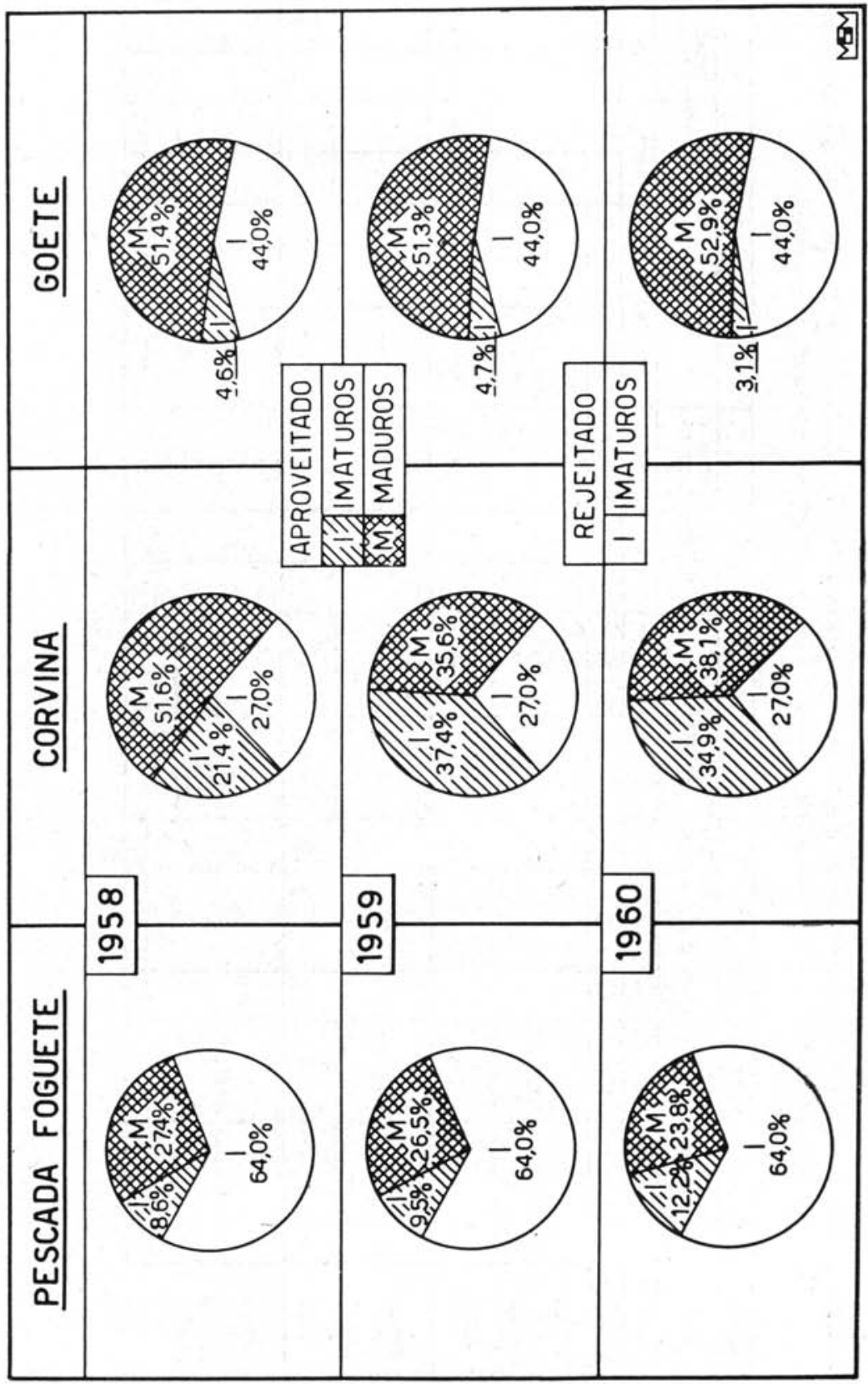

ठ 


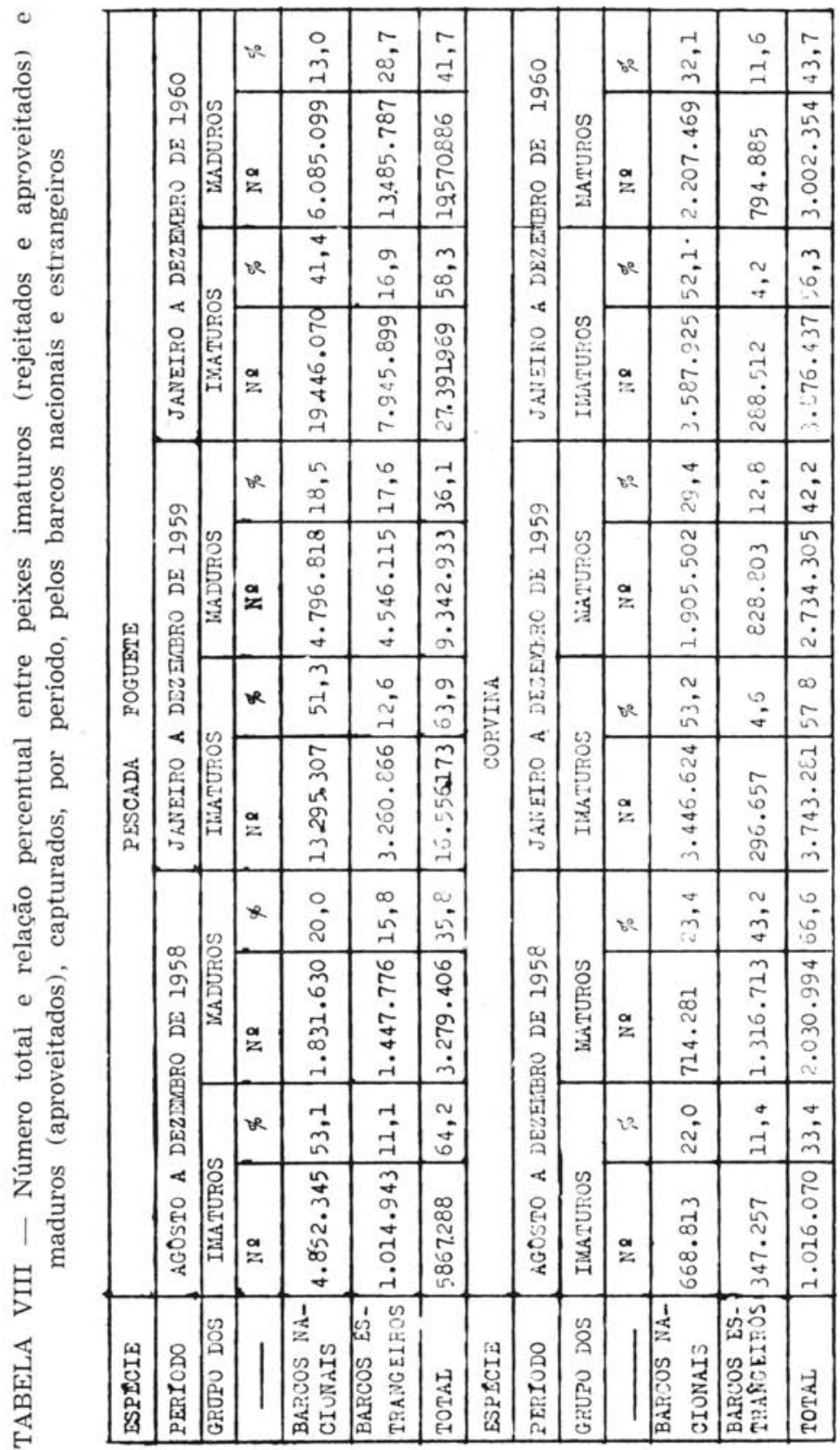




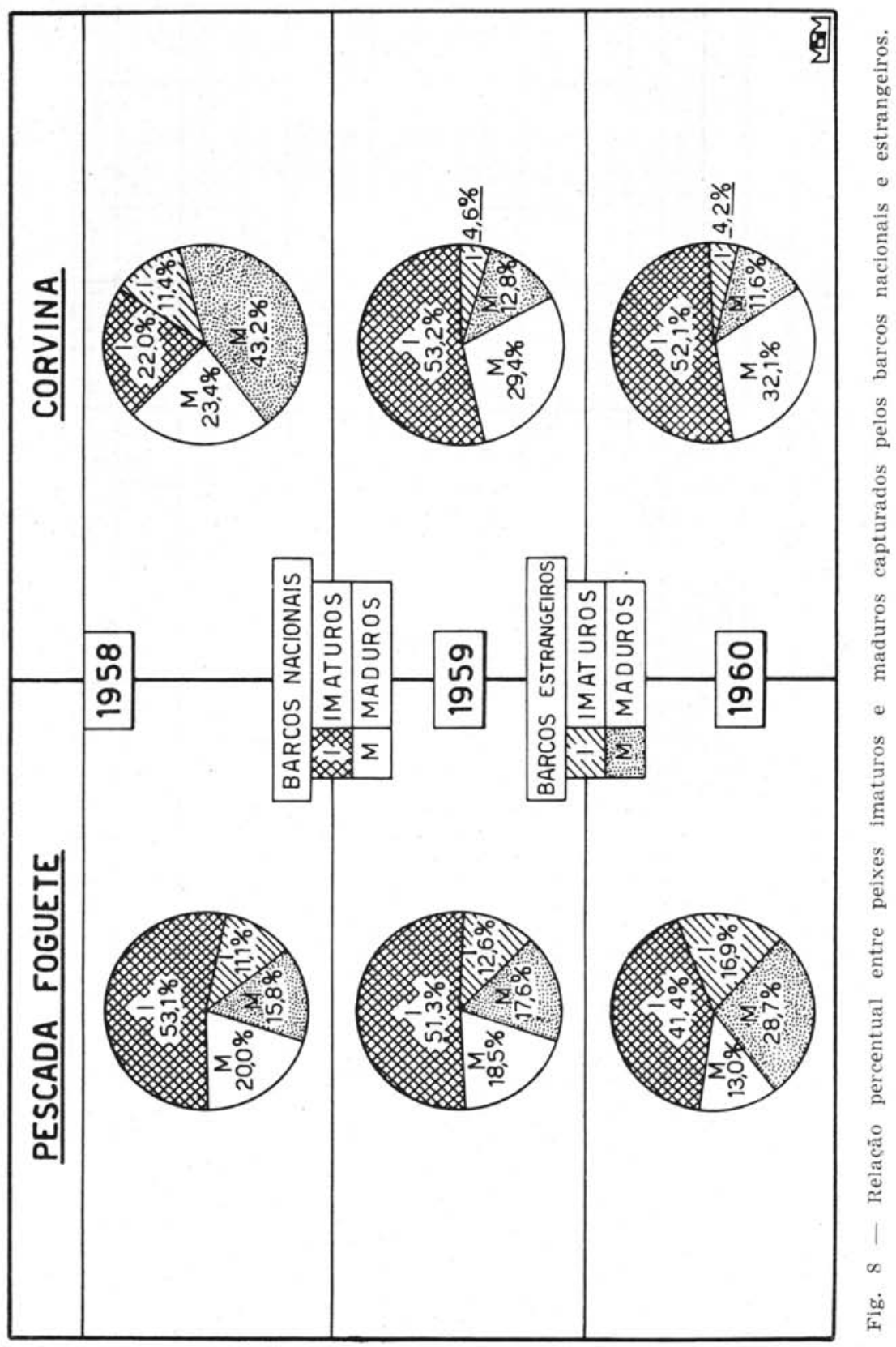

